\title{
Influence of Plant Host and Organ, Management Strategy, and Spore Traits on Microbiome Composition
}

\author{
Kristi Gdanetz, ${ }^{1}$ Zachary Noel, ${ }^{2}$ and Frances Trail ${ }^{1,2, \dagger}$ \\ ${ }^{1}$ Department of Plant Biology, Michigan State University, East Lansing, MI 48824 \\ ${ }^{2}$ Department of Plant Soil and Microbial Sciences, Michigan State University, East Lansing, MI 48824
}

Accepted for publication 22 December 2020.

\section{ABSTRACT}

Microbiomes from maize and soybean were characterized in a long-term three-crop rotation research site, under four different land management strategies, to begin unraveling the effects of common farming practices on microbial communities. The fungal and bacterial communities of leaves, stems, and roots in host species were characterized across the growing season using amplicon sequencing and compared with the results of a similar study on wheat. Communities differed across hosts and among plant growth stages and organs, and these effects were most pronounced in the bacterial communities of the wheat and maize phyllosphere. Roots consistently showed the highest number of bacterial operational taxonomic units compared with aboveground organs, whereas the $\alpha$-diversity of fungi was similar between above- and belowground organs. Network analyses identified putatively influential members of the microbial communities of the three host plant species. The fungal taxa specific to roots, stems, or leaves were examined to determine whether the specificity reflected their life histories based on previous studies. The analysis suggests that fungal spore traits are drivers of organ specificity in the fungal community. Identification of influential taxa in the microbial community and understanding how community structure of specific crop organs is formed will provide a critical resource for manipulations of microbial communities. The ability to predict how organ-specific communities are influenced by spore traits will enhance our ability to introduce them sustainably.

Keywords: crop, management, microbiome, microorganism, mycology, organic amendments, rhizosphere and phyllosphere
Maize, soybean, and wheat are major crops in the United States, with approximately 88, 83, and 47 million acres, respectively, planted annually (USDA-NASS 2016). Fungal and bacterial diseases are the significant causes of losses in these crop systems (Mueller et al. 2018). In the Midwestern United States, the three

${ }^{\dagger}$ Corresponding author: F. Trail; trail@msu.edu

Funding: This work was supported, in part, by the Michigan State University Plant Sciences Fellowship Program, Michigan State University AgBioResearch, the National Science Foundation Long-term Ecological Research Program (DEB 1637653) at the Kellogg Biological Station, and the United States Department of Agriculture National Institute of Food and Agriculture grant MICL08541 to F. Trail.

Author contributions: F.T. and K.G. designed the experiments. K.G. managed the field collections, sample preparation and performed the data analysis. Z.A.N. conducted ternary analysis and interpretation and participated in the writing and editing of the manuscript. K.G. and F.T. interpreted the data and wrote the manuscript.

Current address of Z. Noel: Department of Entomology and Plant Pathology, Auburn University, Auburn, AL 36849.

*The $\boldsymbol{e}$-Xtra logo stands for "electronic extra" and indicates that supplementary tables and supplementary figures are published online.

The author(s) declare no conflict of interest.

(C) 2021 The American Phytopathological Society crops are frequently grown in rotation to preserve soil health and reduce disease. Microbial communities can positively influence multiple plant processes: root-associated microbiota fix nitrogen (Bhuvaneswari et al. 1980; van der Heijden et al. 1998), and leafassociated microbiota play roles in carbon cycling (AbandaNkpwatt et al. 2006; Vorholt 2012) and stimulate plant defenses (Vogel et al. 2016). Surveys of microbial communities on agricultural systems have focused on root-associated microbiota (Gomes et al. 2018; Rojas et al. 2017; Strom et al. 2019), particularly bacterial communities (Mashiane et al. 2017; Rascovan et al. 2016). Studies of fungal communities in row crops have often focused on organ or compartment, most commonly on roots and rhizospheres (Strom et al. 2019) and less commonly on the leaves and phyllospheres (Karlsson et al. 2014, 2017; Sapkota et al. 2017). Several studies have looked at microbial responses to land management or rotation strategies (Karlsson et al. 2017; Longley et al. 2020) but the field sites often are not near replicates; therefore, observed community differences are confounded by divergence in field characteristics (Peiffer et al. 2013; Rascovan et al. 2016). Increased knowledge of the effects of crop rotation on microbiome assembly will inform our ability to manipulate microbiomes for increased yield and disease protection.

Assembly of microbial communities of any plant part results from the distribution of propagules to an appropriate space and their 
ability to colonize. The resulting fungal community has been shown to be affected by a combination of host genetics ( $\mathrm{T}$. Chen et al. 2020; Hassani et al. 2018; Maignien et al. 2014) and dispersal, selection, and drift of propagules (Evans et al. 2017; Oneto et al. 2020; Vellend 2010), all influenced by environmental conditions. A large volume of historic literature, focusing mainly on dispersal of ascomycete and oomycete plant pathogens, has shown that spore morphology (size, shape, and melanization) and dispersal mechanisms (active dispersal, passive dispersal including hypogeous dispersal, and motility) play a critical role in the distribution of fungal propagules (Aylor 2017; Calhim et al. 2018; Deacon 2006; Schumann and D'Arcy 2010). Other studies have focused on the dispersal of basidiospores along with the interactions of spore traits with the environment (Calhim et al. 2018; Halbwachs et al. 2015; Peay et al. 2012; Pringle et al. 2015).

Compared with fungi, bacterial dispersal mechanisms are less varied due to less diverse morphology and modes of distribution. Plant-associated bacteria are presumed to predominantly colonize from the soil (Compant et al. 2010). Chemotaxis driven by bacterial flagella and quorum sensing can affect colonization of the plant surface above- and belowground. Migration to aboveground parts can also occur through endophytic colonization of the vascular system (Lamb et al. 1996). Bacteria are distributed in hotspots across the surface of the aboveground plant parts (Lindow and Brandl 2003), with the bulk of the colonization on lower leaf surfaces (Remus-Emsermann et al. 2014). Furthermore, bacteria can disperse along fungal hyphae, demonstrating the importance of bacterial-fungal interactions for the assembly of the microbiome (Kohlmeier et al. 2005; Zhang et al. 2018).

In the present study, we aimed to conduct a comprehensive analysis of the fungal and bacterial communities of wheat, maize, and soybean across a full 3-year rotation cycle under different land management strategies. Previous studies at the same site characterized wheat and soybean microbiomes within single growing seasons (Gdanetz and Trail 2017; Longley et al. 2020). We investigated the microbial communities associated with each of the plant organs (leaf, stem, and root) and the change in communities across growth stages. To achieve this goal, we analyzed the fungal and bacterial communities of 1-ha replicate plots in a completely randomized block design managed as organic, conventional till, notill, and low input for over 30 years (Hamilton et al. 2015). We compared these microbial communities to our previous studies of the wheat microbial community at the same site. Our analysis of organ-associated microbiomes revealed fungal taxa that are specific to a single plant organ and demonstrates the role of dispersal mechanisms and spore traits associated with these different niches, resulting in the specificity of fungi to above- or belowground plant organs.

\section{MATERIALS AND METHODS}

Site description and sample collection. The Michigan State University W. K. Kellogg Biological Station Long-Term Ecological Research site (KBS-LTER) is located in Hickory Corners, MI, U.S.A. (42.411085, -85.377078). The KBS-LTER Main Cropping System Experiment site has been planted in a wheat-maize-soybean rotation series since 1993, and is organized in randomized, replicated plots under four land management strategies with 6 replicate plots for each strategy ( 24 total plots): $\mathrm{T} 1=$ conventional till, $\mathrm{T} 2=$ no-till, T3 $=$ reduced chemical inputs with red clover cover crop (low input), and T4 = organic with red clover cover crop (Hamilton et al. 2015). Average annual precipitation for this site is $1,005 \mathrm{~mm}$, with approximately half falling as snow (National Climatic Data Center 1980-2010 climate normals for the Gull Lake Biological
Station, https://lter.kbs.msu.edu/research/site-description-andmaps/general-description/climate-normals). The annual precipitation was $1,177,932$, and $1,153 \mathrm{~mm}$ during wheat-, maize-, and soybean-growing years, respectively. Detailed site and management information can be obtained from https://lter.kbs.msu.edu/ research/.

For the 2013 harvest, wheat seed of the cultivar Pioneer 25R39 soft red winter wheat (Pioneer High-Bred International, Inc., Johnston, IA, U.S.A.) were planted in all plots but wheat seed for conventional, no-till, and low-input plots were coated with Gaucho insecticide at purchase (Bayer Crop Science, Research Triangle Park, NC, U.S.A.). These have been previously analyzed and reported (Gdanetz and Trail 2017) but the data were used here as a comparison for the three-crop rotation. For the 2014 harvest, a commercial maize hybrid cultivar, Dekalb DKC52-59 maize hybrid (Monsanto Company, St. Louis, MO, U.S.A.), was planted in plots T1 to T3, and an organic-approved cultivar, Blue River Hybrids 25M75 organic maize (Blue River Organic Seed, Ames, IA, U.S.A.), was planted in T4 plots. For the 2015 harvest, the commercial soybean cultivar Pioneer P22T69R (Roundup Ready) soybean seed (Pioneer High-Bred International, Inc., Johnston, IA, U.S.A.), was planted in the T1 to T3 plots, and Viking Organic Soybean Seed, Variety 0.2265 (Albert Lea Seed, Albert Lea, MN, U.S.A.), was planted in the T4 plots. The conventional, no-till, and low-input management used fungicide- and insecticide-treated maize and soybean seed. Plants were collected at three analogous developmental stages for each host species: late vegetative growth, inflorescence, and early seed, ear, or pod development (Supplementary Table S1). At each developmental stage, three intact plants were removed from each of the 24 plots. Fine and thick roots and aboveground organs (leaves and stems) from each plant were placed in separate sterile sample collection bags (Nasco WhirlPak, Fort Atkinson, WI, U.S.A.) and maintained on ice during transport. Roots were rinsed to remove loosely attached soil, and plants were stored at $-80^{\circ} \mathrm{C}$, then lyophilized. Lyophilized plants were stored at room temperature under a desiccant until grinding and DNA extraction.

Sample and sequence processing. Lyophilized plants were separated by organ (leaf, stem, or root) before grinding with a Retsch Oscillating Mill M400 (Verder Scientific, Newtown, PA, U.S.A.) and DNA was extracted using the Mag-Bind Plant DNA Plus Kit (Omega Bio-tek, Norcross, GA, U.S.A.) following the manufacturer's protocols with the KingFisher Flex (Thermo Fisher Scientific, Waltham, MA, U.S.A.). Fungal internal transcribed spacer (ITS) 2 and bacterial $16 \mathrm{~S}$ ribosomal RNA (rRNA) gene libraries were generated as described previously and sequenced using Illumina MiSeq $2 \times 250$ bp chemistry (Supplementary Table S1) (Gdanetz and Trail 2017; Kozich et al. 2013; Toju et al. 2012). Sequences are available with the National Center for Biotechnology Information Small Read Archive project. Accession numbers for wheat, maize, and soybean are SRP102192, SRP102245, and SRP120500, respectively.

Forward and reverse read pairs from each library were merged with USEARCH (version v8.1.1861) (Edgar 2010; Edgar and Flyvbjerg 2015; Edgar et al. 2011). Low-quality reads, (fastq expected error set to 1.0), and read pairs without mates were discarded (read length was set at $250 \mathrm{bp}$ for $16 \mathrm{~S}$ and $380 \mathrm{bp}$ for ITS2 sequences). The $16 \mathrm{~S}$ and ITS2 libraries from all three host species were concatenated into one large dataset for each barcode region. Sequences were processed as described previously (Gdanetz and Trail 2017). Briefly, the USEARCH pipeline was implemented for chimera filtering and operational taxonomic unit (OTU) assignment, with the cluster threshold set to $97 \%$ similarity. The Ribosomal Database Project Classifier was used for taxonomic 
assignment, with the $16 \mathrm{~S}$ and the UNITE ITS training sets for bacteria and fungi, respectively, customized to include the plant hosts (Cole et al. 2013; Deshpande et al. 2016; Wang et al. 2007). OTUs matching plants, mitochondria, and chloroplasts, unidentified at the kingdom or domain level, or matching nontarget organisms were discarded. Samples were filtered to include OTUs that occurred in at least five samples and this trimmed dataset was used for all downstream analyses.

Analysis of organ-specific OTUs. Organ-specific fungal OTUs were identified during core OTU analysis. To reduce the number of OTUs that were associated with an organ due to chance, such as a bloom of fruiting bodies near plant collection sites, organ-specific lists were further filtered to include OTUs found in a minimum of five replicate plots at the field site. Initial examination of the fungal OTUs using FUNGuild (Nguyen et al. 2016) suggested that there was specificity of taxa to plant organs. To determine whether the organ colonization of fungal OTUs was due to differences in dispersal mechanisms across lineages of fungi, propagule characteristics were defined for organ-specific OTUs with taxonomic assignments through primary literature when available (Supplementary Table S6).

Propagule characteristics were classified into propagule size (length on longest side), cell motility, presence of yeast forms, melanization, and means of dispersal. For spore size, we chose three categories (up to $10 \mu \mathrm{m}, 10$ to $100 \mu \mathrm{m}$, and greater than $100 \mu \mathrm{m}$ ) based upon the natural breaks in spore size occurring between higher taxonomic ranks. Motile spores and basidiospores were not placed in size groups but formed separate groups due to their special modes of dispersal in the former and the unique size constraints in the latter, which are dictated by size limitations and fruiting body structure (Fischer et al. 2010; Galante et al. 2011; StolzeRybczynski et al. 2009). Pigmentation is also characteristic of some types of spores; thus, melanization status was included when known. Dispersal mechanisms included aerial dispersal, water dispersal (due to rain, pools, or flowing water), soil dispersal, and hypogeous. Finally, yeasts are often present on plant surfaces, and we distinguished those species that are often in a yeast form. The category "other" was composed of fungi which had fewer than five representative, significant OTUs in the indicator species analysis or categories with less than than $0.2 \%$ mean relative abundance (RA), which included spores up to $10 \mu \mathrm{m}$ dispersed in the soil or aerially by water; spores up to $10 \mu \mathrm{m}$ melanized and dispersed aerially; spores up to $10 \mu \mathrm{m}$ hypogeous; spores 10 to $100 \mu \mathrm{m}$ dispersed by insects, soil, water, or were hypogeous; spores greater than $100 \mu \mathrm{m}$ dispersed by water or aerially; and yeasts dispersed aerially or by water. Propagule characteristics assigned to OTUs can be found in Supplementary Table S6 and references therein.

After classification of fungal propagule characteristics, an indicator species analysis was conducted to determine which fungal OTUs were significantly associated with a host organ. Samples with fewer than 1,000 reads were removed; then, read counts were normalized using the cumulative sum scaling technique with the 'metagenomeSeq' package (Paulson et al. 2013). Indicator species analysis was performed with the R package 'indicspecies' (version 1.7.6) to identify OTUs significantly associated with host organs (De Cáceres and Legendre 2009). Rare taxa with a mean RA $<10^{-5}$ within each host species were not included in the analysis and a Benjamini-Hochberg $P$ value correction was used for multiple testing. Following indicator species analysis, the compositional abundance of each OTU was plotted in a ternary diagram using 'ggtern' (Hamilton and Ferry 2018) and colored by propagule characteristic categories.

Community analysis. Venn diagrams and tables for core taxa analysis were generated using the gplots package (Warnes et al.
2016) in the R statistical computing environment (version 3.3.3). Before generating bar plots, taxa were merged at the class level. Taxa that were present in less than $3 \%$ of the samples were removed. RAs of taxa were calculated as a percentage of total sequences in each sample. OTUs per sample were normalized with variance-stabilizing normalization and Bonferroni-corrected $P$ values were used to identify significantly different OTUs across samples with the 'DESeq2' package (McMurdie and Holmes 2014).

To determine the effect of management strategy on microbial community diversity, comparison between host species, organs within and between each growth stage, and comparisons between management were made for each host. $\alpha$-Diversity statistics (abundance transformation, observed OTUs, and Shannon's Index) were calculated with the 'phyloseq' package (McMurdie and Holmes 2013). Nonrarefied data were used to calculate the Shannon Diversity Index $\left(H^{\prime}\right)$, an $\alpha$-diversity metric that measures species diversity within a sample (McMurdie and Holmes 2014), and analysis of variance and Tukey's honestly significant difference test were used to determine significance. Nonmetric multidimensional scaling (NMDS) ordination analysis was conducted using Bray-Curtis distance values, a measure of species diversity between communities. Permutational analysis of variance (PERMANOVA) tests were completed using the adonis function in the 'vegan' $\mathrm{R}$ package (Oksanen et al. 2016). Heterogeneity of the variances was calculated using the $\beta$-dispersion function of the 'vegan' package (Oksanen et al. 2016). Figures were generated with the 'ggplot2' package (Wickham 2009).

Putative hub taxa (species that influence the presence of others in an environment) were identified as highly connected nodes based on calculations by Agler et al. (2016). Fungal and bacterial OTU tables were concatenated before calculating the cooccurrence network, and leaf- and stem-specific OTUs were grouped together as phyllosphere samples and filtered to include OTUs with $\geq 20$ reads in $\geq 10$ samples using the SpiecEasi package in $\mathrm{R}$ (Kurtz et al. 2015). Network statistics and network plots were generated using Cytoscape (version 3.5.1) (https://cytoscape.org/). Network statistics, specifically log-transformed degree (number of connections between nodes), betweenness centrality (measure of nodes with shortest connections to other nodes), and closeness centrality (measures distances between nodes), were fit to a normal distribution, and OTUs in the 75th and 95th percentile across all three statistics were identified as putative hub taxa.

\section{RESULTS}

Observed and core taxa. To investigate the effect of crop management strategy (conventional, no-till, low-input, or organic) on microbiomes of leaves, stems, and roots, samples were collected across replicate plots throughout the season at three growth stages (Supplementary Table S2). We analyzed bacterial and fungal communities of maize and soybean grown under the four management strategies over a 2-year period (maize in 2014 and soybean in 2015), using fungal (ITS2) and bacterial (16S) rRNA gene amplicon sequencing. By including sequencing for wheat from the 2013 field season (Gdanetz and Trail 2017), we analyzed one full rotation cycle from this field site. Following filtering and quality control, high-quality reads were identified for fungi and bacteria, respectively, with means of 21,245 fungal and 42,166 bacterial reads per sample. No fungal sequences from soybean T4 stems and roots passed quality control (Supplementary Table S4) and, thus, were not included in the rest of the analysis. In total, 4,739 fungal and 8,942 bacterial high-quality OTUs were identified for maize and soybean combined. Excluding off-target kingdom and domain matches, the combined data from all three crops revealed 
7,233 fungal and 12,673 bacterial OTUs (Supplementary Table S3).

Unique and shared OTUs were compared among the three host species and plant organs (leaves, stems, and roots). Of the bacterial and fungal OTUs, fewer OTUs were unique to soybean plants (Figs. 1 and 2). Bacterial communities were similar across all management strategies within a host species at the class level (Supplementary Fig. S1); however, we observed differences among hosts and organs (Fig. 1). Fungal OTUs were more uniformly distributed across all hosts and management strategies than bacteria.

Highly abundant bacterial classes Actinobacteria, Alphaproteobacteria, Bacilli, Betaproteobacteria, and Gammaproteobacteria
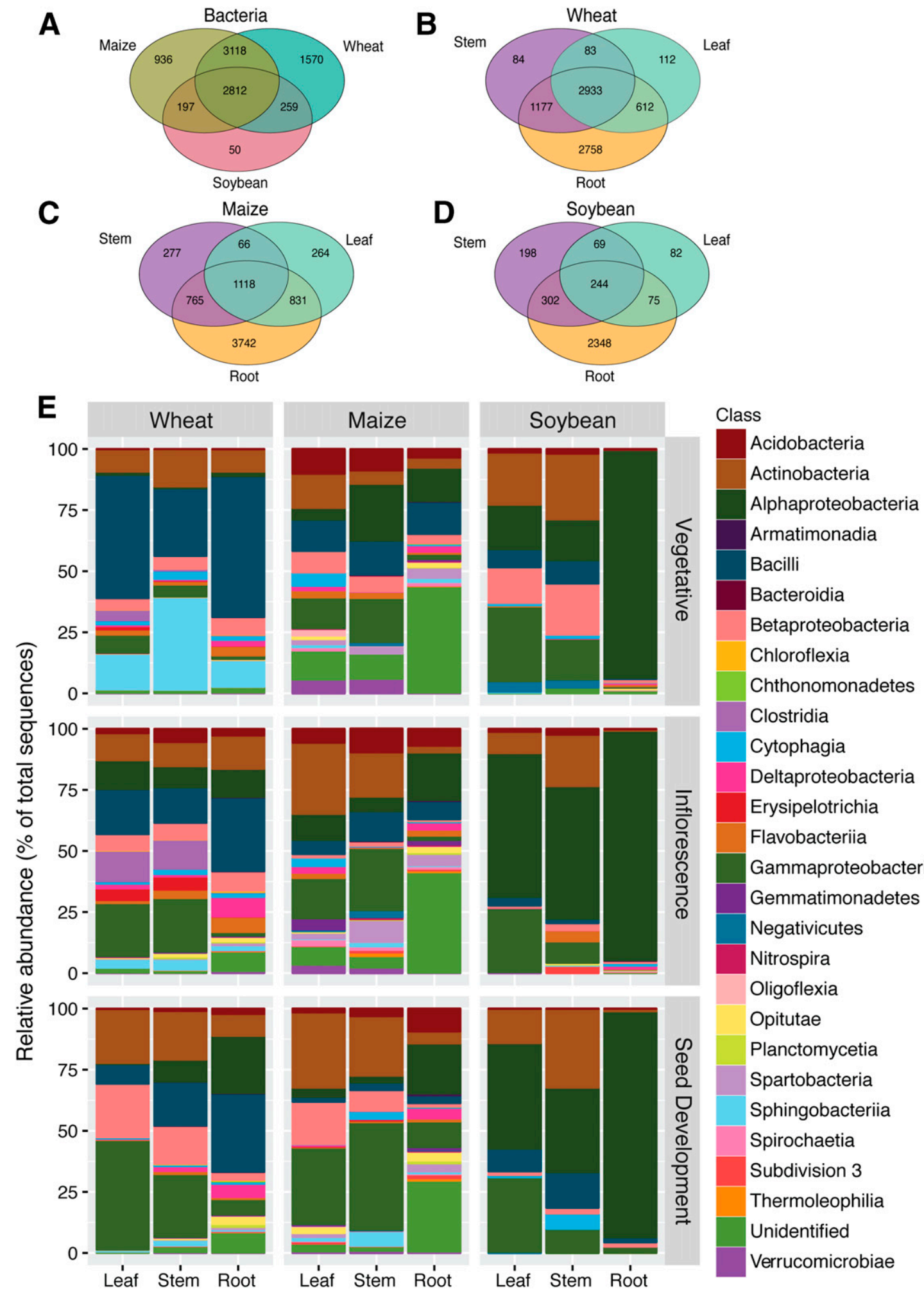

Fig. 1. Distribution of bacterial operational taxonomic units (OTUs) across crops and organs. Shared and unique OTUs across A, whole plants and B, C, and $\mathbf{D}$, organs in wheat, maize, and soybean, respectively. E, Class-level relative abundance of OTUs in bacterial communities across crop, organ, and growth stage. 
were generally shared across all host species (Fig. 1E; Supplementary Fig. S1). Maize and soybean bacterial OTUs showed organ specificity, similar to those observed for the 2013 wheat analysis (Fig. 1B and E) (Gdanetz and Trail 2017). Roots consistently had the most organ-specific bacterial OTUs, with higher numbers of bacterial OTUs unique to roots than shared among organs in either maize or soybean (Fig. 1). Soybean rootscontained $88 \%$ of the host-specific bacterial taxa, compared with $93 \%$ in wheat and $87 \%$ in maize (Fig. 1). In maize roots, 246 OTUs were significantly different in abundance across management
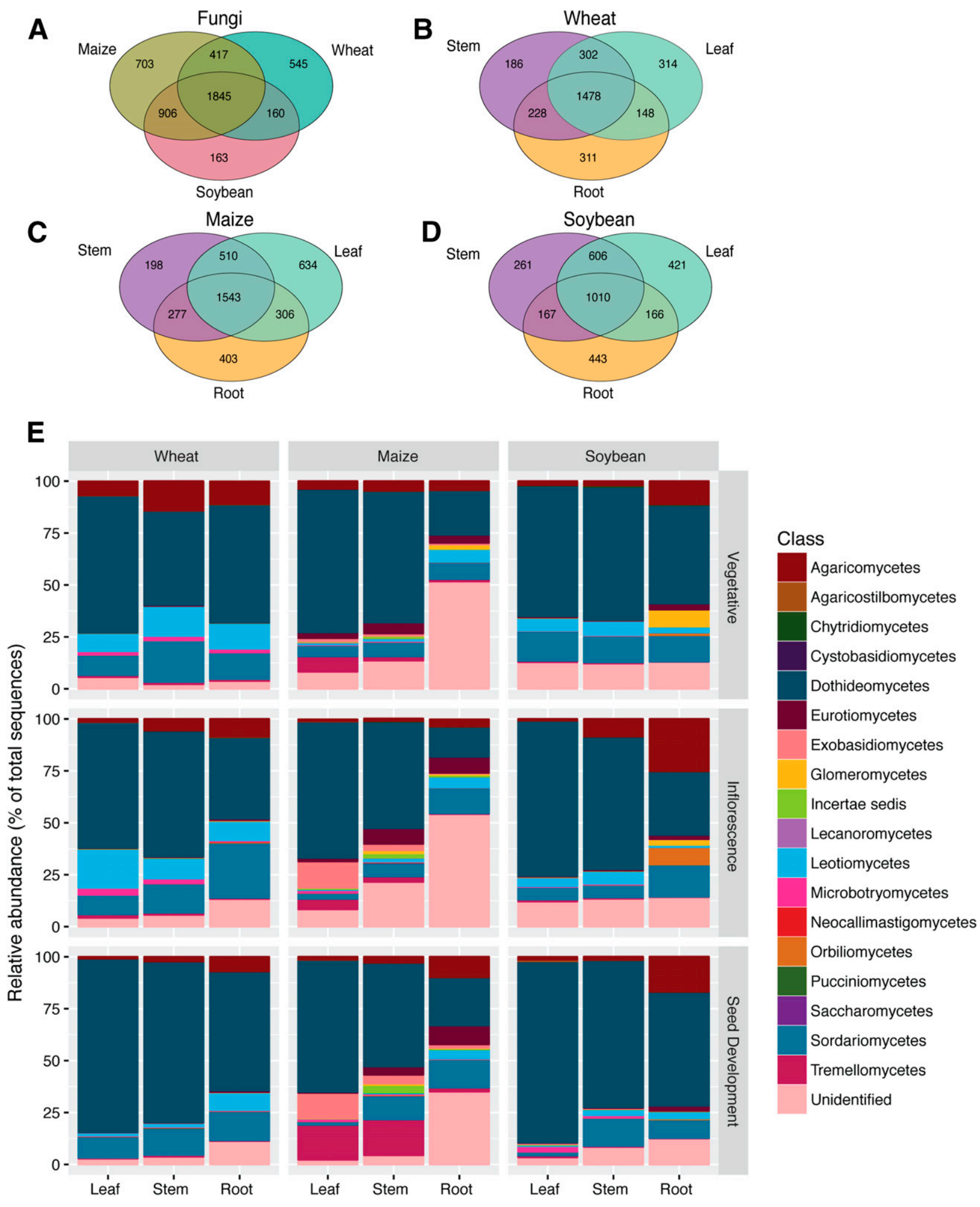

Fig. 2. Distribution of fungal operational taxonomic units (OTUs) across crops and organs. Shared and unique OTUs across A, whole plants and B, C, and D, organs in wheat, maize, and soybean, respectively. E, Class-level relative abundance of OTUs in fungal communities across crops, organs, and growth stages. 
strategies and growth stages $(P<0.01)$ (Supplementary Table S5). In total, 255 bacterial OTUs from roots were identified as significantly different across management strategy and growth stage $(P<$ 0.01) (Supplementary Table S5). The phyllosphere organs (leaves and stems) of each host revealed similar classes of bacterial taxa when compared with the roots of the same host species (Fig. 1; Supplementary Fig. S1). Bacterial community composition of wheat and maize aboveground organs changed with growth stage (Fig. 1E). OTUs found in maize stems were more consistent between no-till and low-input samples than other management strategies (Supplementary Fig. S1). The dominance of Alphaproteobacteria in soybean roots of all management strategies was not surprising because this class includes rhizobia.

At the OTU level, 266 fungal OTUs (5\% of total fungal OTUs) were identified as significantly different $(P<0.05)$ across management strategies and growth stages (Supplementary Table S5). The classes Agaricomycetes, Dothideomycetes, Leotiomycetes, and Sordariomycetes occupied the highest percentages of OTUs for each of the crop organs and growth stages (Fig. 2). Most notable were the Dothidiomycetes, the largest class in the kingdom Fungi and common plant pathogens and melanized endophytes, which dominated all growth stages and treatments (Fig. 2; Supplementary Fig. S2). Also notable is the presence of class Microbotryomycetes, predominantly on wheat in the two earlier stages. These members of the subdivision Pucciniomycotina often present as epiphytic yeasts. Yeasts that inhabit the phyllosphere are well suited to the oligotrophic conditions present on leaf surfaces. They produce extracellular polysaccharides, surfactants, and carotenoid compounds, which may be important for maintaining biofilms and stress tolerance (Cobban et al. 2016; Fonseca and Inácio 2006).

Fungal communities in roots of maize and soybean differed from those found on aboveground organs (Fig. 2). Root communities in wheat also differed from aboveground organs but these observations were dependent on plant age (Fig. 2); aboveground communities of wheat were more similar during vegetative growth (Fig. 2) (Gdanetz and Trail 2017). Root samples of all hosts and growth stages, except the wheat vegetative stage, had a higher abundance of species of Agaricomycetes than did the phyllosphere organs (Figs. 2; Supplementary Fig. S2). Members of the Basidiomycota class Tremellomycetes, which includes plant-associated yeast forms, were highly represented in phyllosphere organs on maize but at very low levels in other samples (Fig. 2; Supplementary Fig. S2). Species of Glomeromycetes (the group containing the arbuscular mycorrhizal fungi) and Orbiliomycetes (nematode-trapping fungi) were more abundant in soybean roots than in other host plant species (Figs. 2; Supplementary Fig. S2).

Analysis of abundance of single OTUs. The most abundant fungal order present was the Pleosporales in the phyllosphere, with 413 OTUs present across all crops. Glomerales in the roots was the next most abundant order, with 109 OTUs. OTUs of the orders Agaricales, Capnodiales, Chaetothryiales, Helotiales, Hypocreales, and Sordariales were the next most abundant, with each of these containing 30 to 70 unique OTUs. Species of the order Sordariales (Sordariomycetes) are predominantly associated with roots.

The most abundant OTU was OTU_2, Epicoccum nigrum, and was specific to leaves: maize $(\mathrm{RA}=13.7 \%)$, soybean $(\mathrm{RA}=5.82 \%)$, and wheat $(\mathrm{RA}=1.57 \%)$. OTU_413 and OTU_804 were found abundantly on soybean stems ( $\mathrm{RA}=8.29$ and $3.08 \%)$, maize stems $\left(\mathrm{OTU} \_804 \mathrm{RA}=1.55 \%\right)$, and leaves of wheat $\left(\mathrm{OTU} \_413 \mathrm{RA}=\right.$ $3.60 \%$ ) (Supplementary Table S6). These OTUs were assigned to Stagonosporopsis loticola (Chen and Kirschner 2018), a lotus pathogen, but are likely to be related members of the Didymellaceae family. OTU_8 (an unidentified basidiomycete) was the second most abundant OTU and was found on maize leaves ( $\mathrm{RA}=11.16 \%$ ) and soybean roots $(\mathrm{RA}=0.53 \%)$. Individual OTUs with high $\mathrm{RA}$ on roots were mainly assigned to order or family, which obscured the specificity of their life history. Interestingly, all seven of the OTUs significantly associated with the stem fell into the division Chytridiomycota. We have assigned these OTUs to the category "zoospores/water" in keeping with the major phenotypes of that phylum (James et al. 2006). None of these OTUs were defined at lower taxonomic ranks and, although three were associated with wheat, three with soybean, and one with maize, they represented seven separately defined OTUs.

Organ-specific OTUs. Analyses of OTUs conducted using higher taxonomic classifications such as in Figure 1 do not supply us with adequate information on the biology of the fungi; therefore, we examined the identity of unique fungal OTUs for each plant organ across all host species (Fig. 3A to C; Table 1), and determined their spore traits and dispersal mechanisms from the literature. Our objective was to evaluate the relationship between fungal distribution and organ specificity. Although many OTUs were shared across organs (Figs. 2A to D and $3 \mathrm{~A}$ and B), there was identifiable organ specificity among the plant-associated fungal taxa. Across all hosts, 2,591 root-, 112 stem-, and 2,257 leaf-specific fungal OTUs were identified. In total, 1,506 root-, 112 stem-, and 1,789- leaf specific OTUs were assigned a taxonomic classification specific enough to determine their spore traits and dispersal mechanisms (Supplementary Table S6); the remaining OTUs could not be assigned spore categories. Categories of propagule characteristics were defined as spore size and type, motility, and predicted means of dispersal, based on the literature. Distribution of propagule characteristics was analyzed to determine whether location of organ-specific taxa aligned with their dispersal and other spore characteristics. Spores from 10 to $100 \mu \mathrm{m}$ made up $57 \%$ of the spores of all taxa identified, and $71 \%$ of leaf-specific taxa, $64 \%$ of stem-specific taxa, and $41 \%$ of root-specific taxa; the majority of taxa from each organ produced predominantly melanized spores and were, at least in part, aerially distributed. These melanized, aerially distributed taxa, together with the taxa-producing spherical spores (mainly very large) associated with the division Glomeromycota ( $28 \%$ of taxa identified as associated with roots), formed the predominant root-specific fungi. Taxa forming spores of up to $10 \mu \mathrm{m}$ represented $9 \%$ of the leaf-specific taxa, $11 \%$ of the stemspecific taxa, and $13 \%$ of the root-specific taxa and fell into several different categories of dispersal, with the largest numbers of OTUs in categories "aerial, soil", "hypogeous", "insect, other", and "up to $10 \mu \mathrm{m}$, lichenized/aerial, soil". Those spores in "aerial, soil" dispersal categories demonstrated a higher distribution to above ground versus belowground ( $74 \%$ versus $26 \%$ in "aerial, soil", and $58 \%$ versus $42 \%$ in the "lichenized/aerial, soil"). Those OTUs in the "hypogeous" and "insect, other" categories showed exclusive distribution to the soil (Supplementary Table S6). Other dispersal categories within the "up to $10 \mu \mathrm{m}$ " group had very low membership.

To visualize the data from the three organs, we used indicator species analysis combined with ternary plots for illustration of the distribution of spore categories for each plant host (Fig. 3C; Supplementary Table S6) and for representation of the distribution of each of the categories among all hosts (Supplementary Fig. S3). The results demonstrated that the microbiomes of maize, soybean, and wheat were distinct between organs. Taxa forming spores up to $10 \mu \mathrm{m}$ in diameter were slightly more likely to be in leaves if aerially distributed and found in soil (13 leaf, 2 stem, and 5 root OTUs) but, if aerial and hypogeous, or dispersed by insects, were exclusively associated with roots (13 hypogeous root OTUs and 10 insect-dispersed root OTUs) (Table 1). The taxa in the division Glomeromycota, which produce very large hypogeous spores, 
were mostly associated with maize roots (33 OTUs) and soybean (43 OTUs), and were highly reduced in wheat roots (5 OTUs) (Supplementary Table S6). Yeasts that were in the division Basidiomycota were more likely to be associated with leaves (20 leaf, 4 stem, and 4 root OTUs; yeast/other or soil) (Table 1). Both roots and leaves were populated with aerially distributed, melanized taxa in the size range of 10 to $100 \mu \mathrm{m}$ (206 leaf, 35 stem, and 102 root OTUs) (Table 1). The zoospore-forming taxa were almost exclusively in roots (0 leaf, 1 stem, and 15 root OTUs), with wheat harboring the majority $(50 \%)$ out of all the host plants (Supplementary Table S6). Maize hosted the greatest numbers of leaf-specific basidiospore-producing taxa. Finally, maize had the most discrete stem-specific taxa and was colonized by more yeast-producing taxa on the leaves and stems than the other plant hosts.

Community diversity. Conventional and transgenic cultivars, in maize and soybean, did not differ significantly in $\alpha$-diversity (as measured by $H^{\prime}$ ) of fungal and bacterial communities when comparing the same growth stage and plant organ (Supplementary
Fig. S4; Supplementary Tables S7 and S8). The effect of cover crop presence or absence, in low-input and organic plots, on fungal and bacterial communities inhabiting each of the organs (leaves, stems, or roots) was compared for each collection period and host species. $H^{\prime}$ of fungal communities was significantly different between plots with and without cover crops in soybean stems during the seed development stage only (Supplementary Fig. S5; Supplementary Tables S7 and S8). $H^{\prime}$ of root bacterial communities during flowering of wheat was significantly lower in plots with cover crops $(P<0.001)$ (Supplementary Fig. S5; Supplementary Tables S7 and S8). There were no other observed differences in $\alpha$-diversity between hosts with and without cover crops (Supplementary Fig. S5; Supplementary Tables S7 and S8).

The effect of management strategies on the microbial community within organs was assessed. Overall, bacterial $\alpha$-diversity of wheat, maize, and soybean roots was significantly higher than $H^{\prime}$ of leaves and stems of these host species; however, there were not significant differences in $H^{\prime}$ of fungal communities between crop organs (Fig. 4C and D; Supplementary Tables S7 and S8). Bacterial $H^{\prime}$ of maize
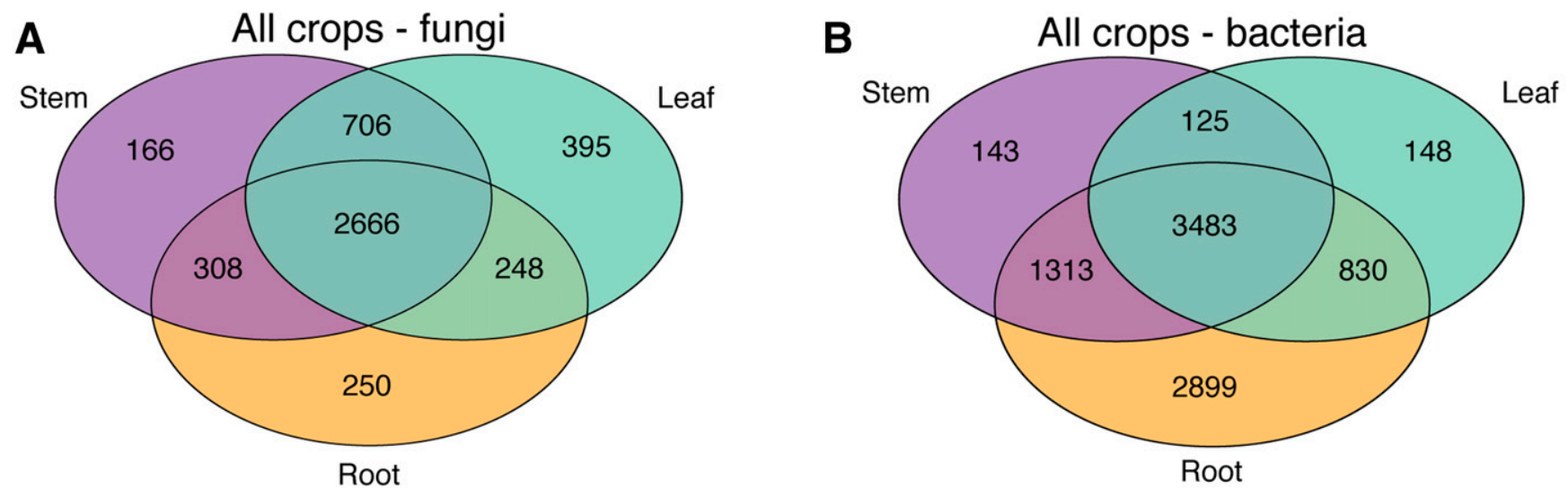

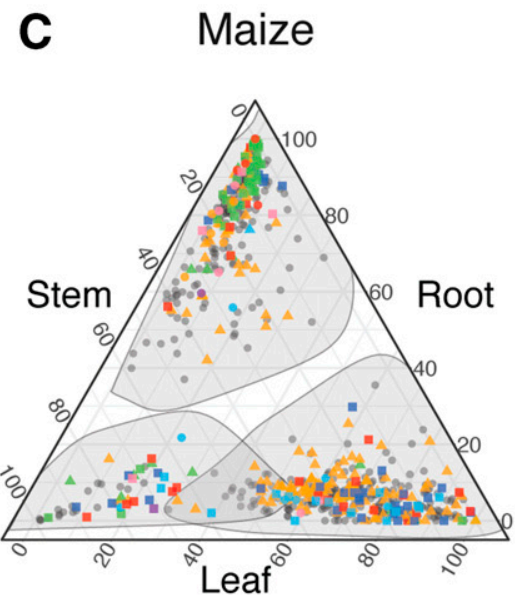

Soybean

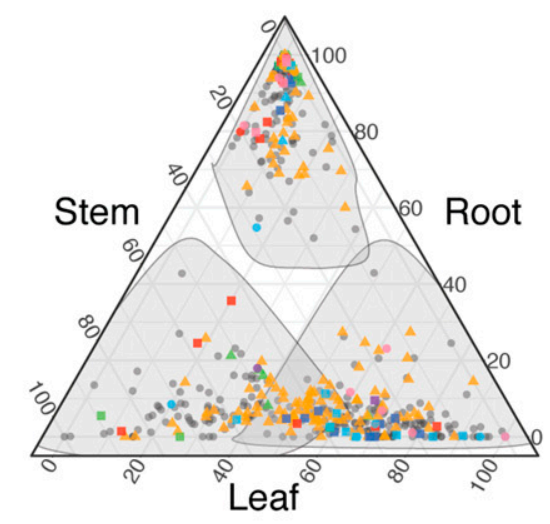

10 to 100 microns / aerial, water
10 to 100 microns, usu. melanized / aerial, water
basidiospores / aerial

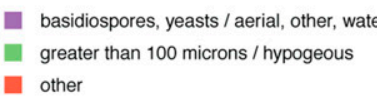

A other/soil

- up to 10 microns / aerial, soil

up to 10 microns / hypogeous, aeria

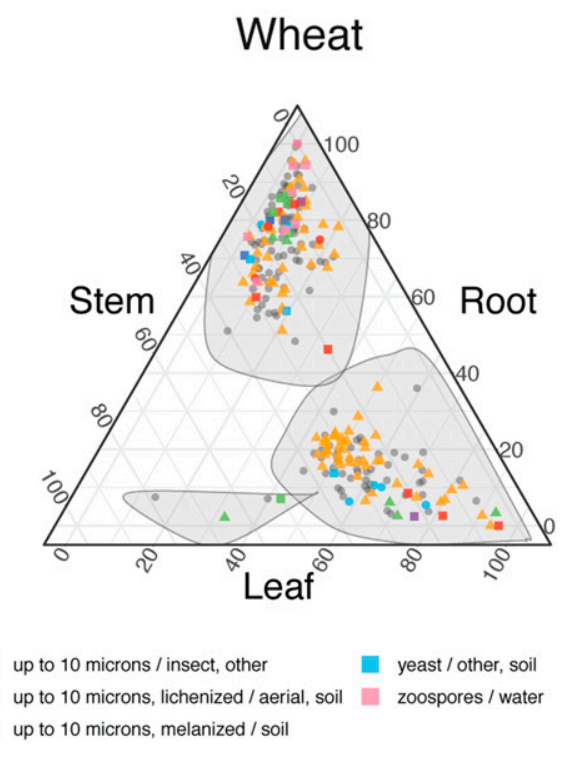

Wheat

Fig. 3. Microbes associated with plant organs. Shared and unique operational taxonomic units (OTUs) of A, fungi and B, bacteria among plant organs. C, Ternary plots illustrating the composition of significant indicator fungal OTUs for each plant organ within each crop. OTUs represented by colored shapes are significant indicators of the plant organ with a Benjamini-Hochberg corrected $P$ value $(\alpha=0.05)$. Shapes are colored by propagule characteristics to illustrate the distribution of propagules within each plant organ. Associations of those OTUs that showed a significant relationship with a specific organ but could not be assigned a taxon are shown as pale gray (not determined [n.d.]/n.d.). Shaded areas encircle the OTUs that are significant indicators for a plant organ. The distribution of propagule characteristics across host species is illustrated in Supplementary Figure S3. Additional information on propagule characteristics and function can be found in Supplementary Table S6. 
roots was higher than that of aboveground organs at all growth stages and under all management strategies. This was a significant increase except in leaves and stems of conventional, no-till, and low-input plots of maize at the vegetative stage (Fig. 4C; Supplementary Fig. S6B; Supplementary Tables S7 and S8). The bacterial diversity of soybean roots was more variable than maize and decreased across the growing season (Fig. 4D; Supplementary Fig. S6B). Bacterial communities of soybean leaves and stems during pod development from all management strategies had significantly higher $H^{\prime}$ compared with roots, except stems from the organic management strategy, due to the dominant presence of rhizobia OTUs (Supplementary Tables S7 and S8). The mean fungal diversity of maize roots trended lower than maize aboveground organs at the vegetative stage but was significantly lower in all managements when compared with fungal diversity of maize leaves from conventional plots (Fig. 4A; Supplementary Tables S7 and S8). Whereas fungal diversity in soybean roots decreased as plants aged, this trend was only significant within the low-input plots (Fig. 4B; Supplementary Tables S7 and S8).

$\beta$-Diversity of microbial communities was visualized with NMDS plots generated from Bray-Curtis distances (Fig. 5; Supplementary Fig. S7). Global analysis revealed clusters for each host species, and segregation was clear for aboveground versus belowground samples in fungi (Fig. 5A; Supplementary Fig. S7A and C). At the vegetative growth stage, wheat bacterial communities from all samples formed a clearly defined cluster, while maize and soybean communities shared a segregation between above- and belowground; however, the separation of wheat from the other host species was lost in the later growth stages (Fig. 5B; Supplementary Fig. S8). Within maize (Supplementary Fig. S7A and B) and soybean (Supplementary Fig. S7C and D) communities, there was clustering of fungal and bacterial communities by plant organs. Centroids of clusters were significantly distinct as determined by PERMANOVA, and variances were also significantly different $(P<$ 0.001) (Supplementary Table S9). Within each growth stage, there was not clear clustering of fungal and bacterial communities by land management strategy, although root samples formed clusters separate from aboveground organs (Supplementary Fig. S8). NMDS plots of management strategies had significantly different centroids $(P<0.01)$; significantly different variances were observed for fungal communities $(P<0.05)$ but were not significant for bacterial communities. Ordination analysis of the effect of cover crop or cultivar on microbial communities showed patterns similar to ordination analysis of management strategy; points segregated by above- and belowground samples (Supplementary Figs. S9 and S10; Supplementary Table S9).

Microbial networks. Networks were generated with OTUs from all management strategies and growth stages. Networks from individual growth stages of one host did not meet filtering requirements; therefore all growth stages were analyzed together. Microbial hubs within networks were defined as nodes with a high degree of connectivity, betweenness centrality, and closeness centrality (Agler et al. 2016) and were composed of species that were likely to influence the presence of others in the environment. Across all three host species, 111 putative hubs were identified and, using more stringent criteria (95th versus 75 th percentiles), the number of hub taxa was reduced to 17 (Table 2). Of the putative hub taxa, nine bacterial hubs were shared between wheat roots and the phyllosphere (Table 2; Fig. 6; Supplementary Fig. S11). All hub taxa in wheat roots were correlated with at least one other hub taxon in the network, and six of these hubs had at least one negative correlation with another node (Fig. 6). Metarhizium was the only hub taxon in the wheat phyllosphere not correlated with other hub taxa (Fig. 6). Of the wheat phyllosphere hub species, Acidovorax sp., Discula destructiva, Helvella dovrensis, Luteolibacter sp., Metarhizium sp., Methylophilus sp., Pedobacter sp., and Taibaiella sp. did not have any negative cooccurrence (Fig. 6).

The bacterial hub taxa in maize roots were frequently positively correlated with other bacterial species. However, bacterial hubs had negative correlations with fungal nodes, with the exception of Myxococcaceae sp. and Pseudonocardineae sp., which were negatively correlated with each other (Supplementary Fig. S12). Species of the division Glomeromycota, which form endomycorrhizal symbioses with plants, clustered in a small isolated network

TABLE 1

Counts of the number of fungal operational taxonomic units (OTUs) significantly associated with leaves, roots, and stems across corn, wheat, and soybean

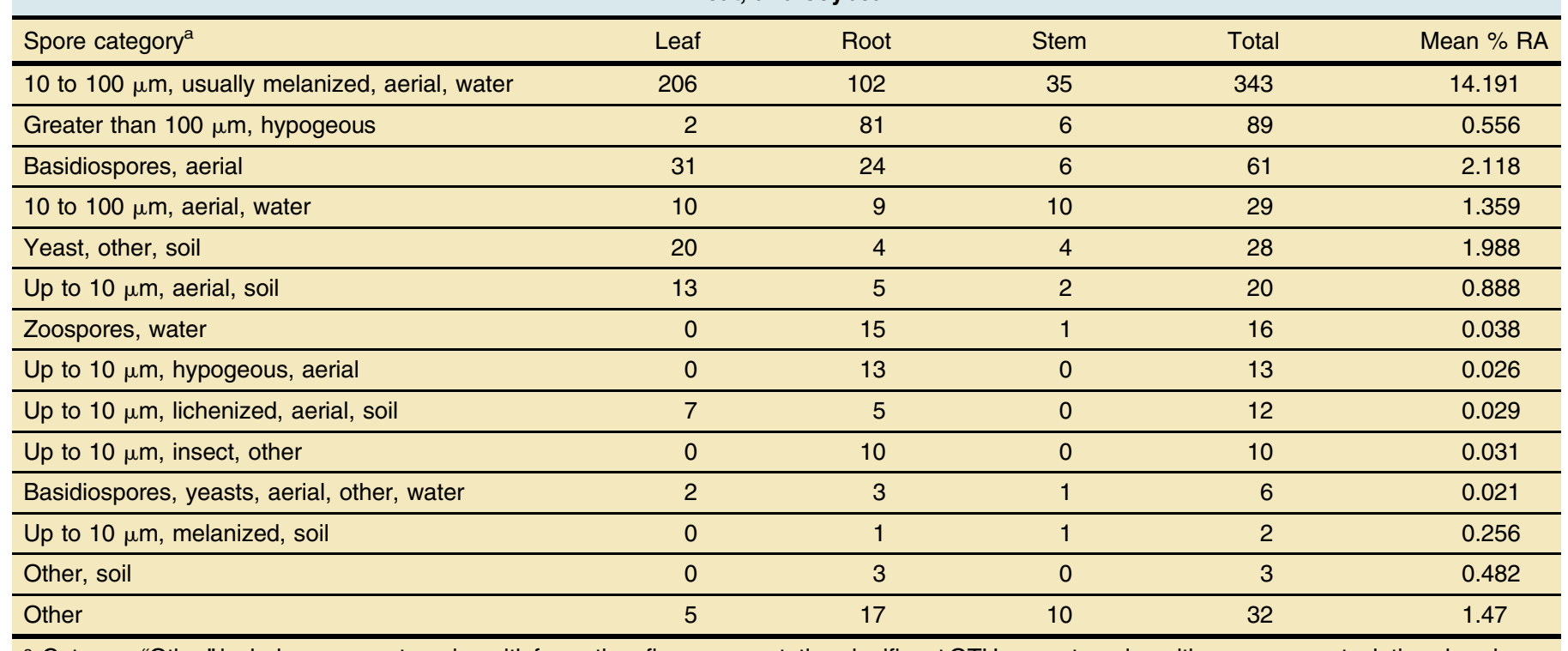

a Category "Other" includes spore categories with fewer than five representative significant OTUs, or categories with mean percent relative abundance $(\mathrm{RA})<0.2$. 
not connected with the main maize root network (Supplementary Fig. S12). Hub taxa in the maize phyllosphere were largely identified as fungi, with only four hubs identified as bacteria (Fig. 7).

Hub taxa were shared across plant organs, and they were also shared across host species. Discula destructiva was identified as a hub taxon in both wheat and maize phyllospheres, and was significantly associated with maize leaves, as shown by indicator species analysis (Supplementary Table S6). Four hub taxa were shared across maize and soybean roots (Table 2). Only one hub taxon, Neosetophoma sp., was shared between soybean root and phyllosphere networks (Figs. 8; Supplementary Fig. S13) and was

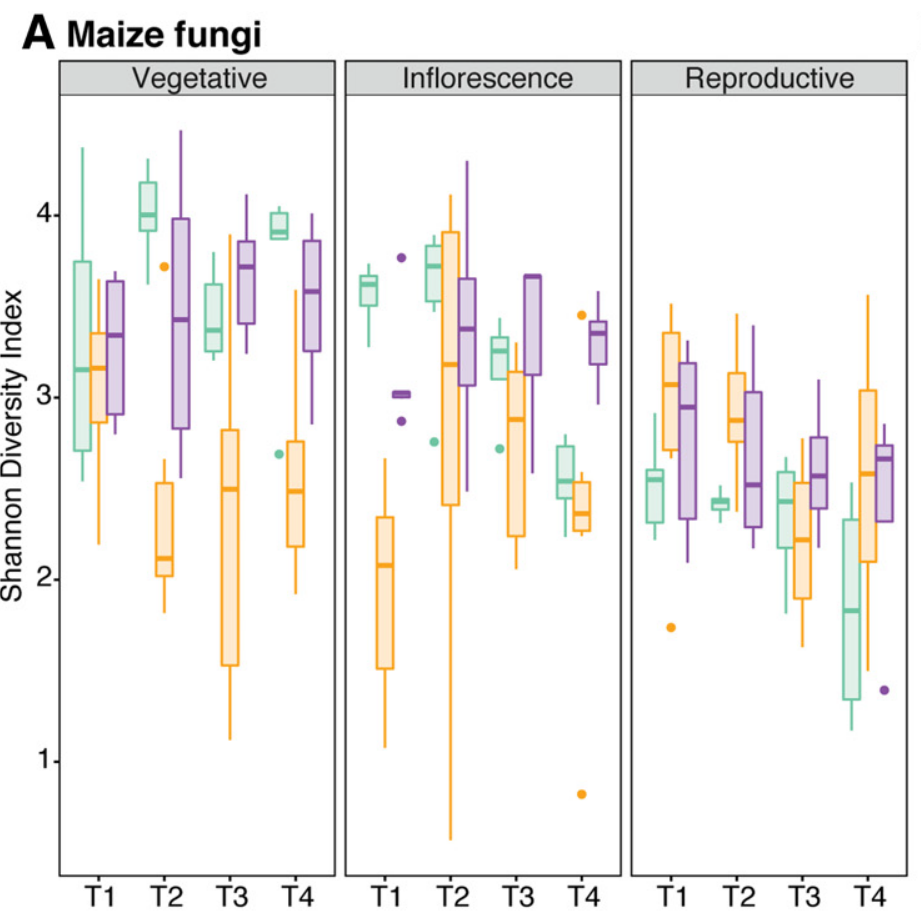

B Soybean fungi
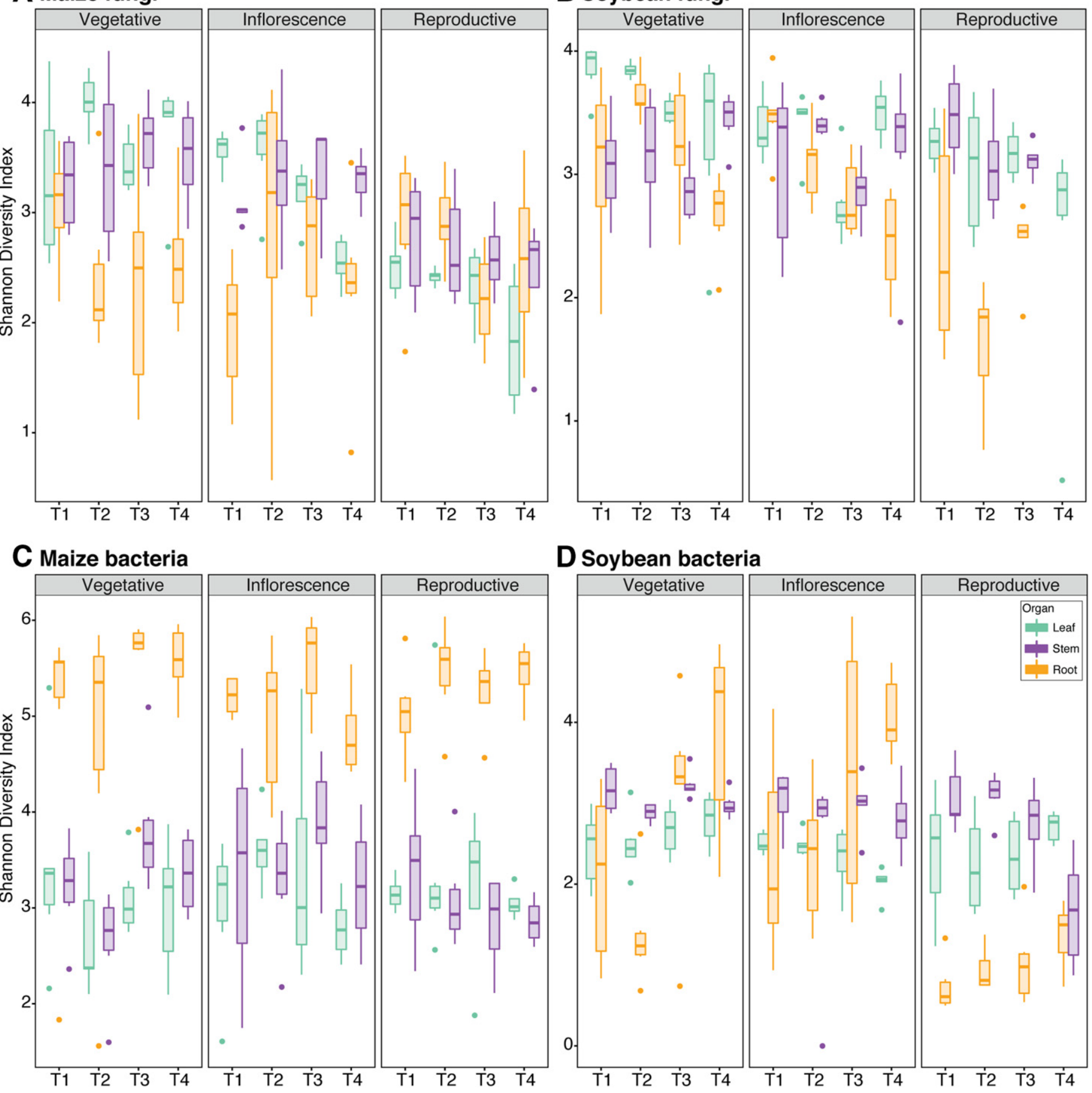

D Soybean bacteria

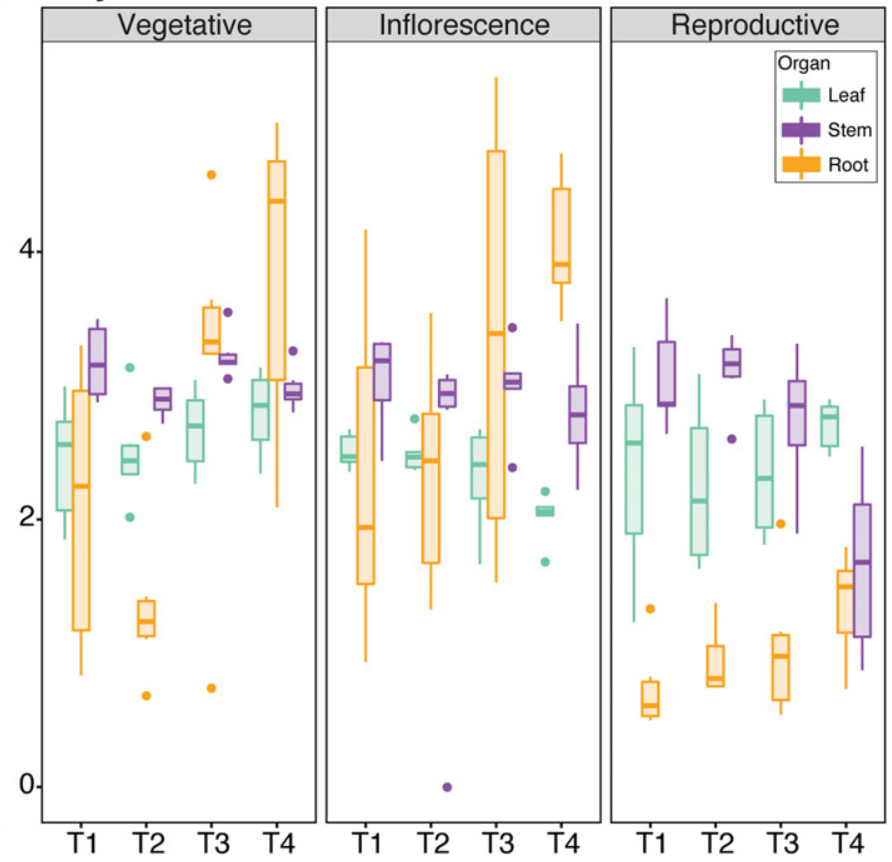

Fig. 4. $\alpha$-Diversity of fungi in $\mathbf{A}$, maize and $\mathbf{B}$, soybean and bacteria in $\mathbf{C}$, maize and $\mathbf{D}$, soybean found on different plant organs across growth stages, under four management strategies. Diversity estimated by the Shannon Diversity Index $\left(H^{\prime}\right)$. T1 = conventional, T2 = no-till, T3 = low input, and T4 = organic. The reproductive growth stage represents early ear development for maize and early pod fill for soybean. Data are represented by six replicates from each stage-management-organ combination. Center line of boxes represents the median value of samples. Upper and lower sides of the boxes represent the third and first quartiles, respectively. Whiskers represent \pm 1.5 times the interquartile range. Data points beyond whiskers represent outliers. Analysis of variance and Tukey's honestly significant difference test were used to test significance $(P<0.05)$. Statistical support is detailed in Supplementary Table S7. 
found to be significantly associated with soybean leaves (Supplementary Table S6). Closely related taxa such as several noduleforming bacterial OTUs (Bradyrhizobium, Mesorhizobium, and Neorhizobium) frequently occurred together in the networks. Fusarium sp. was present in all the cooccurrence networks and was identified as a hub taxon in the wheat phyllosphere.

\section{DISCUSSION}

Here, we present an in-depth comparative analysis of fungal and bacterial microbial communities that colonize the major U.S. row crops (wheat, maize, and soybean) across a 3-year rotation. Although these plant hosts share microbial taxa, the communities of the individual crops also harbor distinct OTUs, as determined by core taxa analysis and diversity metrics. Global analysis revealed distinct community clusters for aboveground versus belowground organs. In a composite analysis of all crops and treatments combined, we also demonstrated that a subset of fungi were specifically and uniquely associated with a single plant organ: leaf, stem, or root. These organspecific taxa represent a small subset of the fungal microbiome yet they provide some clues as to the mechanisms of assembly of the microbiome. For many fungi, the spores are the agents of dispersal, having evolved to optimally distribute propagules to target areas where they can thrive (Calhim et al. 2018; Deacon 1980; Evans et al. 2017; Fischer et al. 2010; Pringle et al. 2015, 2016). Thus, we further examined these taxa in terms of characteristics that affect fungal propagule distribution: spore size and shape, pigmentation, and means of dispersal. From that analysis, we see that the majority of taxa exhibiting organ specificity are associated with spore characteristics that would enhance dispersal to the target organs.

Modes of dispersal can be generalized among the spore types of the major taxa found uniquely on specific plant organs. In our analysis, differentials are greatest among fungi unique to aboveground versus belowground organs. Root-associated arbuscular mycorrhizal fungi of Glomeromycetes tend to generate very large, generally spherical spores (Chaudhary et al. 2020) that commonly remain in the soil where produced (Egan et al. 2014; Warner et al. 1987; Watkinson 2016). However, recent work has shown that several taxa of arbuscular mycorrhizal fungi have spore traits that permit some aerial dispersal, including smaller spores (Chaudhary et al. 2020). Fungi with the spore trait "up to $10 \mu \mathrm{m}$ " had several different categories of dispersal, with the largest numbers of OTUs in the categories "aerial, soil", "hypogeous", "insect, other", and "up to $10 \mu \mathrm{m}$, lichenized/aerial, soil". This spore size appears to very much depend on dispersal mode for targeting location, whereas those categories with "aerial, soil" dispersal demonstrated a higher presence in aboveground versus belowground tissues, and those OTUs in the "hypogeous" and "insect, other" categories showed higher presence in the roots. The physics of aerial dispersal and spore traits do support this distribution (Calhim et al. 2018; Deacon 2006; Pringle et al. 2015; Trail 2007; Trail et al. 2005). Proof that the taxa we have described as organ specific were placed at these organs directly due to means of dispersal and spore traits would necessitate collecting propagules directly as they land and demonstrating that they colonize specific tissues. However, their absence from other organs across 3 years and three host species supports the conclusion that the fungi are relying on these mechanisms for their distribution.

Fungi that dominate the phyllosphere, including leaf pathogens and endophytes, typically produce spores (10 to $100 \mu \mathrm{m})$ that are airborne, and often melanized to protect from UV damage and desiccation (Eisenman and Casadevall 2012; Henson et al. 1999; Jacobson 2000). In our study, these include the rusts and Dothidomycetes. The rusts are notable leaf pathogens with spores known for very long-range dispersal (Brown and Hovmøller 2002; Golan and Pringle 2017). Dothidiomycetes, the largest class of Ascomycota, includes Alternaria spp. (pigmented, airborne leafinfecting fungi) (Pastor and Guarro 2008) and the frequently occurring Dothidiomycetes orders Pleosporales and Capnodiales (Haridas et al. 2020), with a significant majority of OTUs associated with leaves. Members of order Agaricales are distributed between leaves and roots. Their presence in roots as well as leaves may
A Fungi

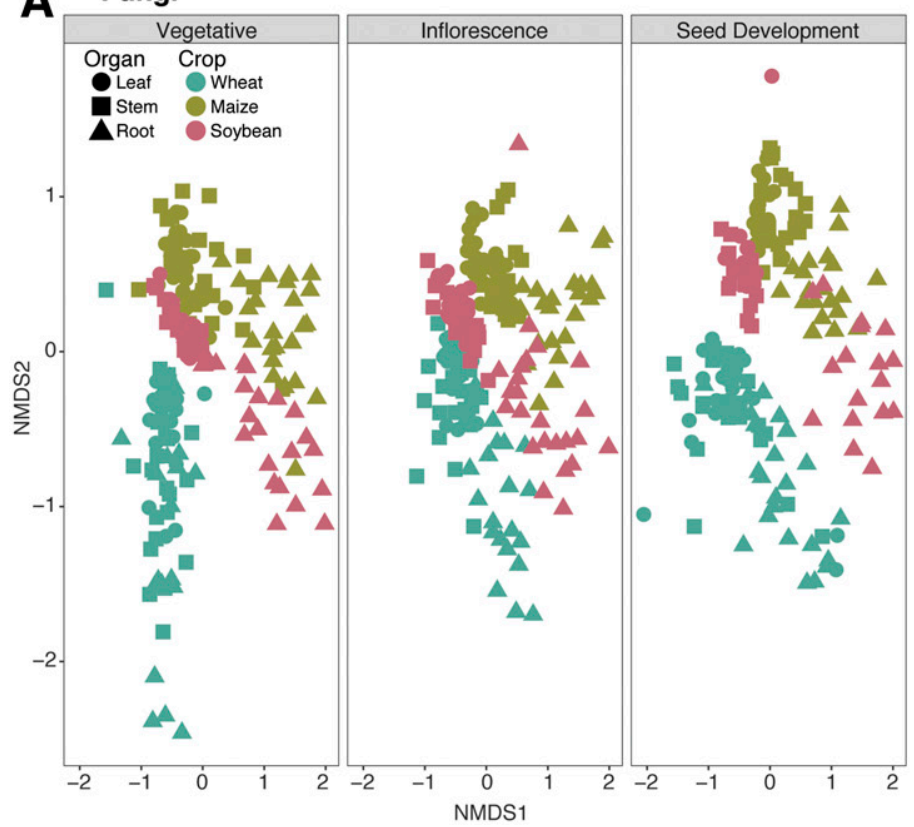

B Bacteria

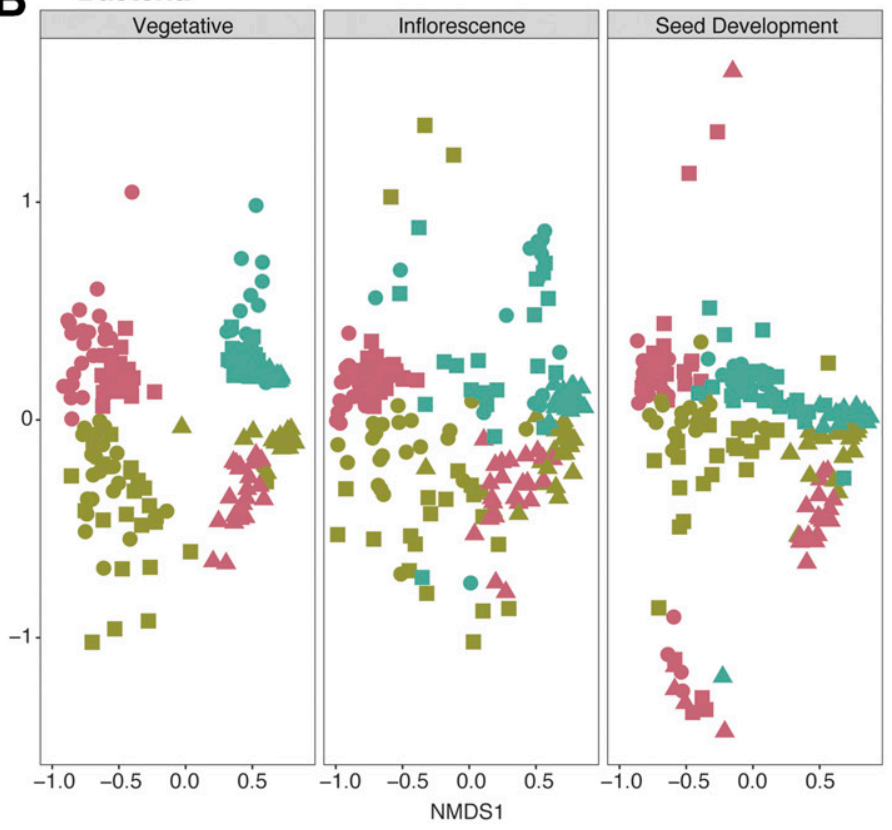

Fig. 5. Effect of growth stage on $\beta$-diversity of $\mathbf{A}$, fungal and $\mathbf{B}$, bacterial communities on all host species. Nonmetric multidimensional scaling (NMDS) calculated by Bray-Curtis distance. Statistical support is detailed in Supplementary Table S9. 
TABLE 2

Hub taxa by host species and organ at the MSU-LTER

Crop, organ, taxa ${ }^{a}$

Wheat

Root

Acidimicrobineae sp.

Acidovorax sp.

Asticcacaulis sp.

Brevundimonas $\mathrm{sp}$.

Caulobacter sp.

Cercospora olivascens ${ }^{b}$

Cytophaga sp.

Devosia sp.

Dioszegia hungarica $^{\mathrm{b}}$

Dongia sp.

Dyadobacter sp. *

Ferruginibacter sp.

Flavobacterium $\mathrm{sp} .{ }^{*}$

Fusarium pseudensiforme ${ }^{\mathrm{b}}$

Glarea lozoyensis ${ }^{\mathrm{b}}$

Janthinobacterium sp.

Labilitrichaceae sp.

Massilia sp. *

Methylophilus sp.

Micrococcineae sp. *

Mucilaginibacter sp.

Novosphingobium sp.

Pedobacter sp. *

Phialemonium globosum ${ }^{\mathrm{b}}$

Polaromonas sp. *

Propionibacterineae sp.

Pseudomonas sp.

Pseudonocardineae sp.

Puccinia recondita ${ }^{\mathrm{b}}$

Ralstonia sp. *

Rhodoferax sp.

Sedimentibacter $\mathrm{sp}$.

Sphingomonas sp.

Taibaiella sp.

Tardiphaga sp.

Variovorax sp. *

Phyllosphere

Acidovorax sp.

Aquabacterium sp.

Devosia sp.

Discula destructiva $^{\mathrm{b}}$

Dyadobacter sp.

Ferruginibacter sp.

Flavobacterium $\mathrm{sp}$.

(Continued)
TABLE 2

(Continued)

Crop, organ, taxa ${ }^{a}$

Helvella dovrensis ${ }^{\mathrm{b}}$

Luteolibacter sp.

Massilia sp.

Metarhizium anisopliae ${ }^{\mathrm{b}}$

Methylophilus sp.

Micrococcineae sp. *

Pedobacter sp.

Polaromonas sp. *

Rhizobium sp. *

Septoria glycinicola ${ }^{\mathrm{b}}$

Taibaiella sp.

Tardiphaga sp.

Maize

Acidovorax sp.

Alternaria alternata ${ }^{\mathrm{b}}$

Aquabacterium sp.

Brachyphoris oviparasitica $^{\mathrm{b}}$

Bradyrhizobium sp.

Devosia sp.

Dyadobacter sp.

Labrys sp.

Methylophilus sp.

Myxococcaceae sp.

Propionibacterineae sp.

Pseudoduganella sp. *

Pseudonocardineae sp. *

Rhizobium sp.

Sphingomonas sp.

Sporobolomyces coprosmae

Streptomycineae sp.

Phyllosphere

Cladonia sp. $^{\mathrm{b}}$

Diaporthe caulivora ${ }^{\mathrm{b}}$

Discula destructivab

Exophiala pisciphila

Kinneretia sp.

Kluyvera sp.

Lactococcus sp.

Lophiostoma macrostomum ${ }^{\mathrm{b}}$

Ophiognomonia sogonovip

Paraconiothyrium hawaiiense ${ }^{\mathrm{b}}$

Ralstonia sp.

Schizophyllum commune ${ }^{\mathrm{b}}$

Stagonosporopsis loticola ${ }^{\mathrm{b}}$

Talaromyces aculeatus ${ }^{\mathrm{b}}$

(Continued on next page) 
TABLE 2 (Continued from previous page)

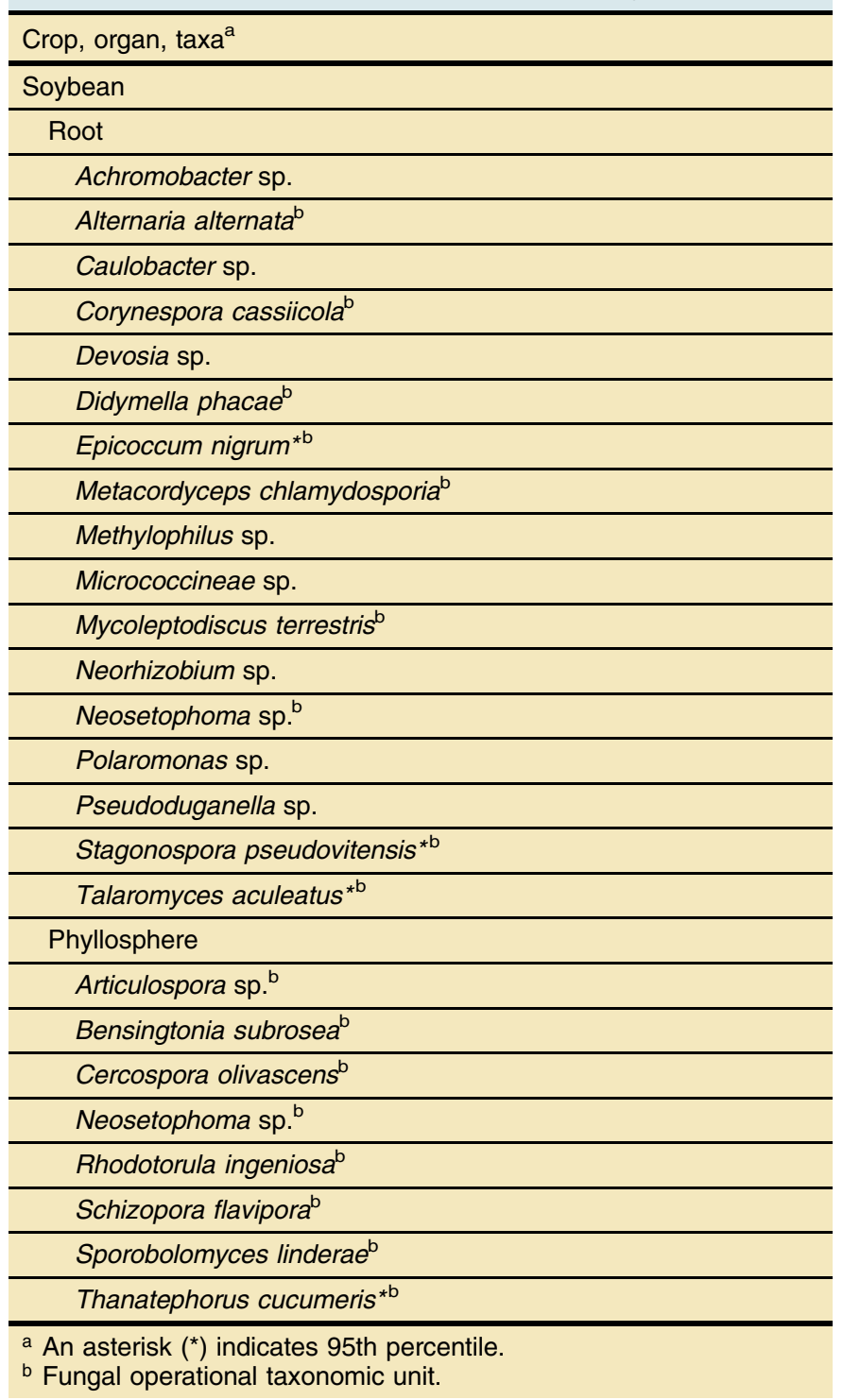

reflect their abundant distribution under the leaf canopy, with basidiocarps forming on the soil surface through colonization of rotting plant tissue, and firing spores using the requisite available moisture (Webster et al. 1984). The lower apparent distribution of this group to wheat may reflect differences in temporal microbial patterns and the fullness of the canopy. Winter wheat was planted at this site, requiring fall plantings and overwintering of young plants, with the first wheat collection occurring before collection of the first growth stages of maize and soybean. Further study is warranted to determine whether the reduced colonization of wheat is due to host genetics or environmental factors.

Bacterial diversity has most often been studied in the roots (Morris et al. 2017), and our results show that the greatest reservoirs of bacterial diversity are the roots of soybean (71\% of OTUs are root specific) and maize (53\% of OTUs are root specific). However, a larger proportion of bacterial OTUs is shared among the three organs in wheat (only 36\% are root specific). Many previous studies have indicated that bacteria mainly colonize through the roots and, of these, a few continue to colonize upward to the phyllosphere (Compant et al. 2010). There are several recent publications suggesting the importance of bacterial diversity in the soil for maintaining plant productivity (Q. L. Chen et al. 2020; Lau and Lennon 2012), and bacterial diversity in the phyllosphere has been shown to be essential for ecosystem productivity (LaforestLapointe et al. 2017), in which the endophytic population, is in part, nurtured by the plant (T. Chen et al. 2020). Further research is needed to determine whether bacteria have different roles in wheat versus soybean and maize based on which organ harbors the most diversity.

Our findings did not provide strong evidence that management strategies alter microbial diversity more than effects of plant organ or host species. Our data suggest that root-associated microbial communities are recruited by the plant hosts and selectively colonize the endophytic compartment. In this study and others, the influence of management strategies on root-associated or root endophytic compartments of row crops is minimal and community differences at these sites are more strongly influenced by the host plant (Naylor et al. 2017). Studies that describe an influence of management on plant-associated microbiota of row crops have been confined to the rhizosphere or bulk soil (Peiffer et al. 2013; Strom et al. 2019; Wattenburger et al. 2019). Additionally, the influence of management on phyllosphere microbiota has been found to vary by crop and season, with some years exhibiting a greater signature of management system than others (Gdanetz and Trail 2017; Longley et al. 2020; Sapkota et al. 2015). Although not directly tested in this study, the patterns of organ and host specificity observed support selective colonization of the root endophytic compartment.

We demonstrated that root-associated microbial communities are distinct from those of the phyllosphere in the three-crop rotation at the KBS-LTER site. Studies that analyze microbial communities across multiple organs, tissues, or compartments on the same plant often show that there are distinct communities across these niches (Coleman-Derr et al. 2015; Gdanetz and Trail 2017; Longley et al. 2020; Ottesen et al. 2013; Strom et al. 2019). Yet, until very recently, studies analyzing soil and rhizosphere microbial communities (Copeland et al. 2015; de Souza et al. 2016; Gomes et al. 2018; Rojas et al. 2017; Strom et al. 2019) have been far more common than studies of phyllosphere communities. Although the rhizosphere and roots have been found to have a higher abundance and diversity of plant-associated bacteria (present study) (Longley et al. 2020) and fungi (Ottesen et al. 2013) compared with the phyllosphere, microbes inhabiting aboveground plant organs and compartments are also important to plant health (RemusEmsermann and Schlechter 2018; Ryffel et al. 2016; Vorholt 2012). Research on model systems shows that phyllosphere microbes can influence disease occurrence and nutrient cycling (Abanda-Nkpwatt et al. 2006; Delmotte et al. 2009; Vorholt 2012), and some microbes have a life cycle that is not captured by a soil- or root-associated phase; for example, important plant pathogens such as rust fungi (Webster and Weber 2007).

Although, in this study, the conventional, no-till, and low-input managements included fungicide- and insecticide-treated seed, there were no controls to assess the direct impact of fungicide treatments on the seed microbiome. Noel et al. (2020) did not detect a difference in oomycete composition in the soybean seedling rhizosphere with or without antioomycete chemical seed treatments. Nettles et al. (2016) have demonstrated that fungicide seed treatments affect the rhizosphere fungal community of maize and soybean but had differential effects on the phyllosphere, as tested during the vegetative growth phase. Therefore, the effect of fungicide seed treatments on the microbiome may be contextual. Studies in mature plants have not been reported. Surprisingly little information is available on the effects of seed treatments on nonpathogenic fungi in the microbiome (Lamichhane et al. 2020). This is an area worthy of further exploration. 
Our findings indicate that fungal diversity in maize and soybean decreases across the growing season, while bacterial diversity remains constant in these two plant hosts. Some aspects of microbial diversity - specifically, the $\alpha$-diversity described in this studyappear to vary temporally across the seasons but this may also be an artifact of seasonal changes such as temperature and moisture (Lauber et al. 2013). Previous studies examining changes in plantassociated microbial communities in a variety of crops over the course of a growing season have not identified a consistent trend. Some studies found increasing community diversity over time in apples (Shade et al. 2013) and winter wheat (Gdanetz and Trail 2017), whereas decreases in diversity have been documented in soybean and sugarcane (Copeland et al. 2015; Rascovan et al. 2016), and no significant changes were found in spring wheat (Sapkota et al. 2017). Additional studies are needed to examine how temporal plant microbial community dynamics of row crops are being influenced by maturation (and likely senescence) of the host plant and environmental factors such as intensity and duration of light, temperature, and moisture. Environmental changes are likely to affect individual microbial species differently. Computer

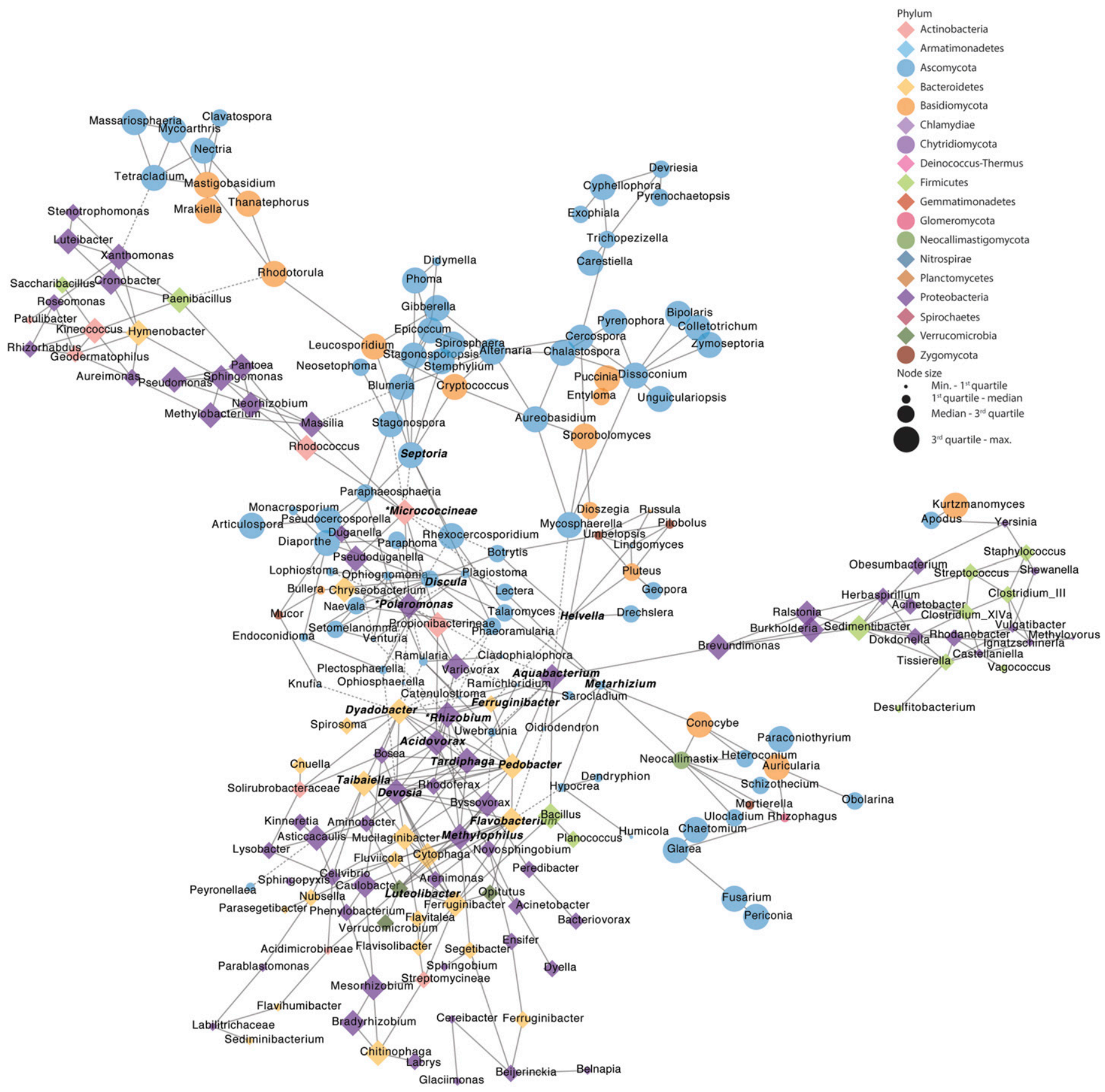

Fig. 6. Cooccurrence network of taxa in wheat phyllosphere. Bacterial operational taxonomic units (OTUs) are represented by diamond shapes, fungal OTUs are represented by circles, and nodes are colored by class. Solid lines indicate positive correlation and dashed lines indicate a negative correlation between OTUs. Node size indicates relative abundance, bold node labels indicate hub taxa at the 75th percentile, and node labels marked with an asterisk indicate hub taxa at the 95th percentile. 
modeling of the plant microbiome suggests that initial colonizers influence final community structure (Evans et al. 2017). Further investigations should be conducted to experimentally determine the effect of random colonization by microbes on the composition of the community at important plant life stages. An understanding of the mechanisms by which the initial colonizers influence final community composition will have implications for community manipulation in both field crops and synthetic environments such as greenhouses or hydroponic systems.

Hub taxa are important members of the plant-associated microbiota that can influence final community composition and plant health (Agler et al. 2016). In the current study, putative hub taxa identified in the plant organs of one host species were not always shared across all others. However, these taxa are commonly occurring OTUs found across all hosts and management strategies. In addition, the fungal hub species included pathogens of other plant species. For example, Discula destructiva, a hub species of both the wheat and maize phyllosphere, causes dogwood anthracnose. In previous studies, the presence of nonhost pathogen hubs has been shown to prevent infection by another pathogen (Agler et al. 2016; Chen et al. 2018), perhaps via induced resistance. As observed in this study and previously described (Berry and Widder 2014), closely related species designated by OTUs of rhizobia, wood rot fungi, and mycorrhizal fungi frequently cooccur in network

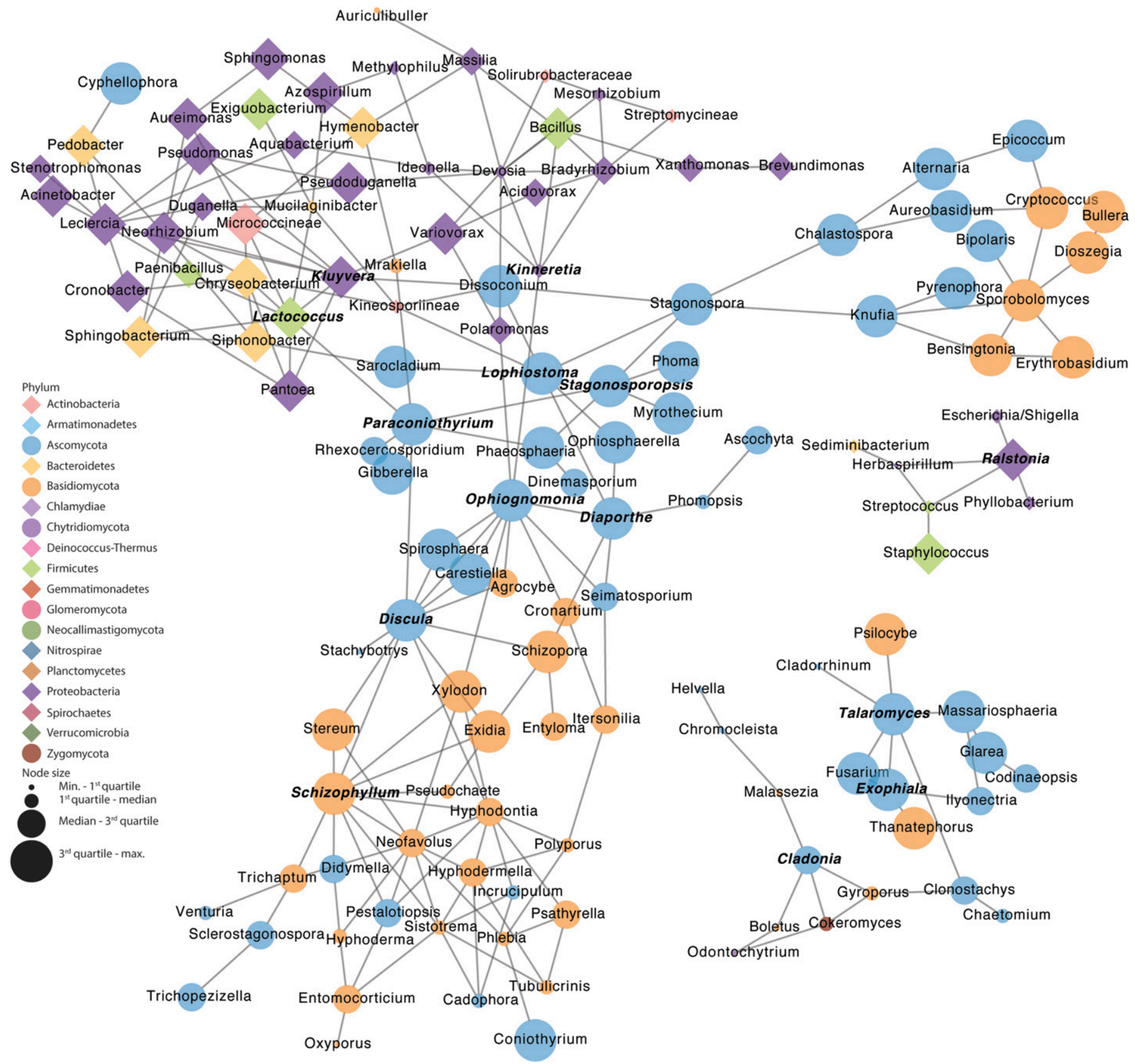

Fig. 7. Cooccurrence network of taxa in maize phyllosphere. Bacterial operational taxonomic units (OTUs) are represented by diamond shapes, fungal OTUs are represented by circles, and nodes are colored by class. Solid lines indicate positive correlation, and dashed lines indicate a negative correlation between OTUs. Node size indicates relative abundance, bold node labels indicate hub taxa at the 75th percentile, and node lables marked with an asterisk indicate hub taxa at the 95th percentile. 
analyses. Also demonstrated here and shown with inferred networks (Agler et al. 2016), microorganisms interact with each other across kingdoms and, thus, it is important to examine cross-kingdom interactions. Hub taxa identified in this study, with few exceptions, were also identified as significantly associated with a specific plant organ by indicator analysis, coupled with their specific means of distribution which target them to that organ. These organisms warrant further study to determine their roles in the microbiomes of healthy plants. Confirmation of hub taxa and understanding of their influence on community composition will be important for community-scale microbial manipulation to improve agriculture, including in precision agricultural approaches (Tackenberg et al. 2016).

This study shows that plant organs (leaves, stems, and roots) have distinct microbial communities. Plant-associated microbial communities arise from the microbial reservoir of the surrounding ecosystem but, for fungi, spore traits maximize their ability to target specific organs. Assembly of microbial communities has been shown to also be affected by host genetics (T. Chen et al. 2020; Hassani et al. 2018; Maignien et al. 2014). Research has indicated that the host can selectively manipulate colonization by some microbes and this selection may be in the form of seed or root exudates that recruit microbes for better (Wu et al. 2015) or for worse (Nelson 2004). Host genotype has also been shown to have a role in phyllosphere mycobiome (Sapkota et al. 2015) and, in particular, leaf chemistry has been shown to suppress spore germination (Barilli et al. 2016). Although host genetics can be at least partially controlled by breeding, intentional manipulation of the microbiome is less straightforward. A recent study shows that, in addition to host genotype, the order of species arrival affects the phyllosphere fungal community outcome (Leopold and Busby 2020). As we show here, fungi evolve to distribute where they will thrive; therefore, dispersal also plays a role in developing the fungal community. This suggests that those species with adaptations that allow them early targeted arrival will have more success in predominating in their host plants. Only a single year was examined for each host, and additional years are in progress to examine the formation of the microbiomes in the three-crop rotation to better resolve factors involved in organ-specific communities and the effect of individual hosts. Our long-term goal is the formation and stability of constructed microbial communities under the influence of climate change.

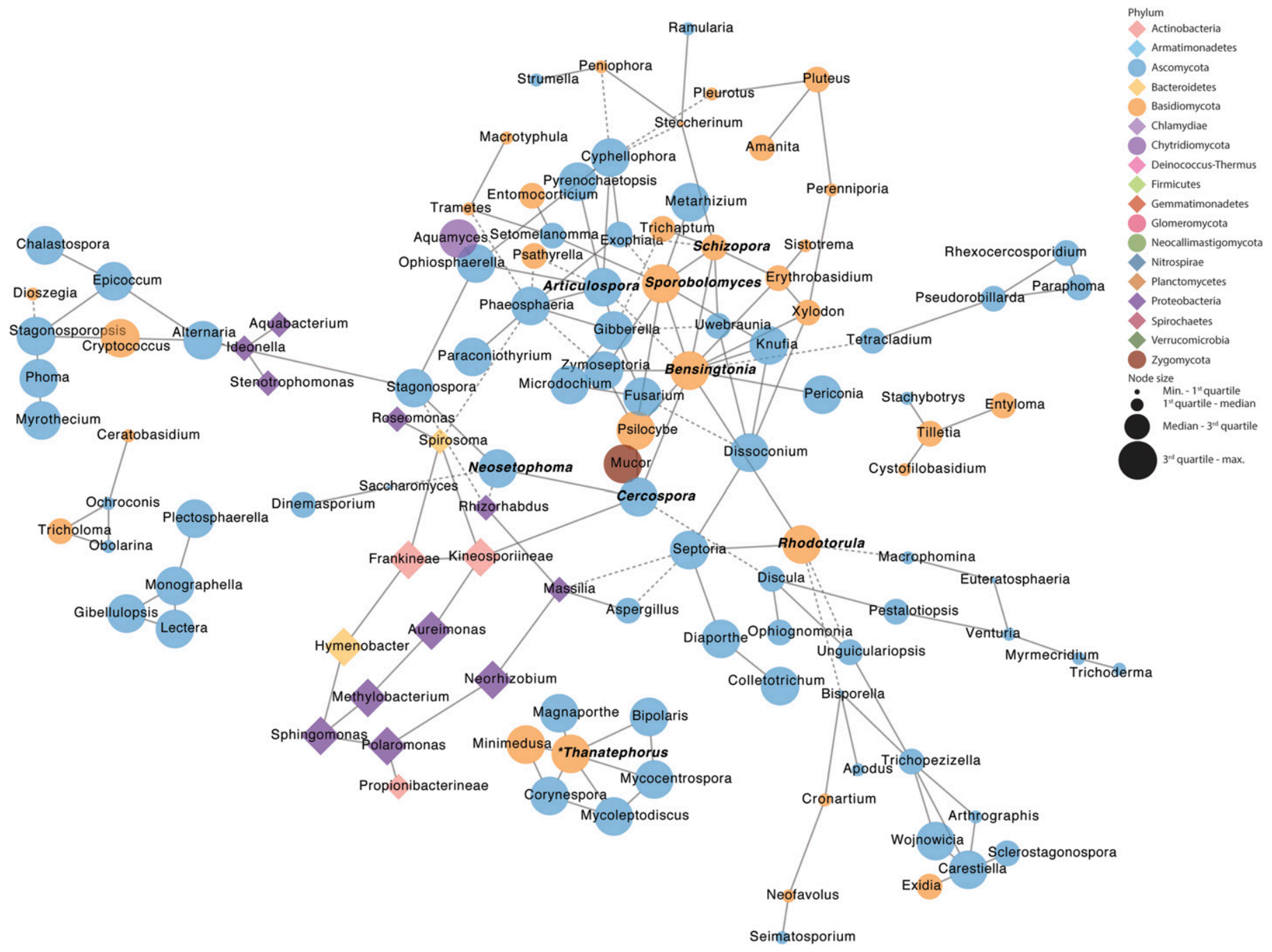

Fig. 8. Cooccurrence network of taxa in soybean phyllosphere. Bacterial operational taxonomic units (OTUs) are represented by diamond shapes, fungal OTUs are represented by circles, and nodes are colored by class. Solid lines indicate positive correlation, and dashed lines indicate a negative correlation between OTUs. Node size indicates relative abundance, bold node labels indicate hub taxa at the 75th percentile, and node lablels marked with an asterisk indicate hub taxa at the 95th percentile. 


\section{ACKNOWLEDGMENTS}

We thank M. Roth for assistance in collecting soybean samples.

\section{LITERATURE CITED}

Abanda-Nkpwatt, D., Musch, M., Tschiersch, J., Boettner, M., and Schwab, W. 2006. Molecular interaction between Methylobacterium extorquens and seedlings: Growth promotion, methanol consumption, and localization of the methanol emission site. J. Exp. Bot. 57:4025-4032.

Agler, M. T., Ruhe, J., Kroll, S., Morhenn, C., Kim, S. T., Weigel, D., and Kemen, E. M. 2016. Microbial hub taxa link host and abiotic factors to plant microbiome variation. PLoS Biol. 14:e1002352.

Aylor, D. E. 2017. Aerial Dispersal of Pollen and Spores. American Phytopathological Society, St. Paul, MN, U.S.A.

Barilli, E., Cimmino, A., Masi, M., Evidente, M., Rubiales, D., and Evidente, A. 2016. Nat. Prod. Commun. 11:1343-1347.

Berry, D., and Widder, S. 2014. Deciphering microbial interactions and detecting keystone species with co-occurrence networks. Front. Microbiol. 5: $1-14$.

Bhuvaneswari, T. V., Turgeon, B. G., and Bauer, W. D. 1980. Early events in the infection of soybean (Glycine max L. Merr) by Rhizobium japonicum. Plant Pathol. 66:1027-1031.

Brown, J. K. M., and Hovmøller, M. S. 2002. Aerial dispersal of pathogens on the global and continental scales and its impact on plant disease. Science 297: 537-541.

Calhim, S., Halme, P., Petersen, J. H., Læssøe, T., Bässler, C., and HeilmannClausen, J. 2018. Fungal spore diversity reflects substrate-specific deposition challenges. Sci. Rep. 8:5356.

Chaudhary, V. B., Nolimal, S., Sosa-Hernández, M. A., Egan, C., and Kastens, J. 2020. Trait-based aerial dispersal of arbuscular mycorrhizal fungi. New Phytol. 228:238-252.

Chen, K.-L., and Kirschner, R. 2018. Fungi from leaves of lotus (Nelumbo nucifera). Mycol. Prog. 17:275-293.

Chen, Q. L., Ding, J., Zhu, Y. G., He, J. Z., and Hu, H. W. 2020. Soil bacterial taxonomic diversity is critical to maintaining the plant productivity. Environ. Int. 140:105766.

Chen, T., Nomura, K., Wang, X., Sohrabi, R., Xu, J., Yao, L., Paasch, B. C., Ma, L., Kremer, J., Cheng, Y., Zhang, L., Wang, N., Wang, E., Xin, X.-F., and He, S. Y. 2020. A plant genetic network for preventing dysbiosis in the phyllosphere. Nature 580:653-657.

Chen, Y., Wang, J., Yang, N., Wen, Z., Sun, X., Chai, Y., and Ma, Z. 2018. Wheat microbiome bacteria can reduce virulence of a plant pathogenic fungus by altering histone acetylation. Nat. Commun. 9:3429.

Cobban, A., Edgcomb, V. P., Burgaud, G., Repeta, D., and Leadbetter, E. R. 2016. Revisiting the pink-red pigmented basidiomycete mirror yeast of the phyllosphere. MicrobiologyOpen 5:846-855.

Cole, J. R., Wang, Q., Fish, J. A., Chai, B., McGarrell, D. M., Sun, Y., Brown, C. T., Porras-Alfaro, A., Kuske, C. R., and Tiedje, J. M. 2013. Ribosomal Database Project: Data and tools for high throughput rRNA analysis. Nucleic Acids Res. 42:D633-D642.

Coleman-Derr, D., Desgarennes, D., Fonseca-Garcia, C., Gross, S., Clingenpeel, S., Woyke, T., North, G., Visel, A., Partida-Martinez, L. P., and Tringe, S. G. 2015. Plant compartment and biogeography affect microbiome composition in cultivated and native Agave species. New Phytol. 209:798-811.

Compant, S., Clément, C., and Sessitsch, A. 2010. Plant growth-promoting bacteria in the rhizo- and endosphere of plants: Their role, colonization, mechanisms involved and prospects for utilization. Soil Biol. Biochem. 42:669-678. doi:

Copeland, J. K., Yuan, L., Layeghifard, M., Wang, P. W., and Guttman, D. S. 2015. Seasonal community succession of the phyllosphere microbiome. Mol. Plant-Microbe Interact. 28:274-285.

De Cáceres, M., and Legendre, P. 2009. Associations between species and groups of sites: Indices and statistical inference. Ecology 90:3566-3574.

de Souza, R. S. C., Okura, V. K., Armanhi, J. S. L., Jorrín, B., Lozano, N., da Silva, M. J., González-Guerrero, M., de Araújo, L. M., Verza, N. C., Bagheri, H. C., Imperial, J., and Arruda, P. 2016. Unlocking the bacterial and fungal communities assemblages of sugarcane microbiome. Sci. Rep. 6:28774.

Deacon, J. W. 1980. Introduction to Modern Mycology, 7th Ed. Blackwell Science Publications, London, U.K.

Deacon, J. W. 2006. Chapter 10. Fungal spores, spore dormancy, and spore dispersal. Pages 184-212 in: Fungal Biology, 4th Ed. Blackwell Publishing, Malden, MA, U.S.A.
Delmotte, N., Knief, C., Chaffron, S., Innerebner, G., Roschitzki, B., Schlapbach, R., von Mering, C., and Vorholt, J. A. 2009. Community proteogenomics reveals insights into the physiology of phyllosphere bacteria. Proc. Natl. Acad. Sci. U.S.A. 106:16428-16433.

Deshpande, V., Wang, Q., Greenfield, P., Charleston, M., Porras-Alfaro, A., Kuske, C. R., Cole, J. R., Midgley, D. J., and Tran-Dinh, N. 2016. Fungal identification using a Bayesian classifier and the Warcup training set of internal transcribed spacer sequences. Mycologia 108:1-5.

Edgar, R. C. 2010. Search and clustering orders of magnitude faster than BLAST. Bioinformatics 26:2460-2461.

Edgar, R. C., and Flyvbjerg, H. 2015. Error filtering, pair assembly and error correction for next-generation sequencing reads. Bioinformatics 31 : 3476-3482.

Edgar, R. C., Haas, B. J., Clemente, J. C., Quince, C., and Knight, R. 2011. UCHIME improves sensitivity and speed of chimera detection. Bioinformatics 27:2194-2200.

Egan, C., Li, D.-W., and Klironomos, J. 2014. Detection of arbuscular mycorrhizal fungal spores in the air across different biomes and ecoregions. Fungal Ecol. 12:26-31.

Eisenman, H. C., and Casadevall, A. 2012. Synthesis and assembly of fungal melanin. Appl. Microbiol. Biotechnol. 93:931-940.

Evans, S., Martiny, J. B., and Allison, S. D. 2017. Effects of dispersal and selection on stochastic assembly in microbial communities. ISME J. 11: 176-185.

Fischer, M. W. F., Stolze-Rybczynski, J. L., Cui, Y., and Money, N. P. 2010. How far and how fast can mushroom spores fly? Physical limits on ballistospore size and discharge distance in the Basidiomycota. Fungal Biol. 114:669-675.

Fonseca, Á., and Inácio, J. 2006. Phylloplane yeasts. Pages 263-301 in: Biodiversity and Ecophysiology of Yeasts. G. Péter and C. Rosa, eds. Springer, Berlin, Heidelberg, Germany.

Galante, T. E., Horton, T. R., and Swaney, D. 2011. 95\% of basidiospores fall within $1 \mathrm{~m}$ of the cap: A field- and modeling-based study. Mycologia 103: $1175-1183$.

Gdanetz, K., and Trail, F. 2017. The wheat microbiome under four management strategies, and potential for endophytes in disease protection. Phytobiomes. 1: 158-168.

Golan, J. J., and Pringle, A. 2017. Long-distance dispersal of fungi. Pages 309-333 in: The Fungal Kingdom. J. Heitman, B. Howlett, P. Crous, E. Stukenbrock, T. James, and N. Gow, eds. ASM Press, Washington, DC, U.S.A. doi:

Gomes, A. E., Lana, U. G. P., Quensen, J. F., de Sousa, S. M., Oliveria, C. A., Guo, J., Guimarães, L. J. M., and Tiedje, J. M. 2018. Root-associated microbiome of maize genotypes with contrasting phosphorus use efficiency. Phytobiomes J. 2:129-137.

Halbwachs, H., Brandl, R., and Bässler, C. 2015. Spore wall traits of ectomycorrhizal and saprotrophic agarics may mirror their distinct lifestyles. Fungal Ecol. 17:197-204.

Hamilton, N. E., and Ferry, M. 2018. ggtern: Ternary Diagrams using ggplot2. J. Stat. Softw. 87:1-17.

Hamilton, S. K., Doll, J. E., and Robertson, P. G., eds. 2015. The Ecology of Agricultural Landscapes: Long-Term Research on the Path to Sustainability. Long-Term Ecological Research Network Series. Oxford University Press, Oxford, U.K.

Haridas, S., Albert, R., Binder, M., Bloem, J., LaButti, K., Salamov, A., Andreopoulos, B., Baker, S. E., Barry, K., Bills, G., Bluhm, B. H., Cannon, C., Castanera, R., Culley, D. E., Daum, C., Ezra, D., González, J. B., Henrissat, B., Kuo, A., Liang, C., Lipzen, A., Lutzoni, F., Magnuson, J., Mondo, S. J., Nolan, M., Ohm, R. A., Pangilinan, J., Park, H.-J., Ramírez, L., Alfaro, M., Sun, H., Tritt, A., Yoshinaga, Y., Zwiers, L.-H., Turgeon, B. G., Goodwin, S. B., Spatafora, J. W., Crous, P. W., and Grigoriev, I. V. 2020. 101 Dothideomycetes genomes: A test case for predicting lifestyles and emergence of pathogens. Stud. Mycol. 96:141-153.

Hassani, M. A., Durán, P., and Hacquard, S. 2018. Microbial interactions within the plant Holobiont. Microbiome 6:58.

Henson, J. M., Butler, M. J., and Day, A. W. 1999. The dark side of the mycelium: Melanins of phytopathogenic fungi. Annu. Rev. Phytopathol. 37: 447-471.

Jacobson, E. S. 2000. Pathogenic roles for fungal melanins. Clin. Microbiol. Rev. 13:708-717.

James, T. Y., Letcher, P. M., Longcore, J. E., Mozley-Standridge, S. R., Porter, D., Powell, M. J., Griffith, G. W., and Vilgalys, R. 2006. A molecular phylogeny of the flagellated fungi (Chytridiomycota) and description of a new phylum (Blastocladiomycota). Mycologia 98:860-871. 
Karlsson, I., Friberg, H., Kolseth, A.-K., Steinberg, C., and Persson, P. 2017. Organic farming increases richness of fungal taxa in the wheat phyllosphere. Mol. Ecol. 26:3424-3436.

Karlsson, I., Friberg, H., Steinberg, C., and Persson, P. 2014. Fungicide effects on fungal community composition in the wheat phyllosphere. PLoS One 9: e111786.

Kohlmeier, S., Smits, T. H. M., Ford, R. M., Keel, C., Harms, H., and Wick, L. Y. 2005. Taking the fungal highway, mobilization of pollutant-degrading bacteria by fungi. Environ. Sci. Technol. 39:4640-4646.

Kozich, J. J., Westcott, S. L., Baxter, N. T., Highlander, S. K., and Schloss, P. D. 2013. Development of a dual-index sequencing strategy and curation pipeline for analyzing amplicon sequence data on the MiSeq Illumina sequencing platform. Appl. Environ. Microbiol. 79:5112-5120.

Kurtz, Z. D., Müller, C. L., Miraldi, E. R., Littman, D. R., Blaser, M. J., and Bonneau, R. A. 2015. Sparse and compositionally robust inference of inference of microbial ecological networks. PLOS Comput. Biol. 11:e1004226-25.

Laforest-Lapointe, I., Paquette, A., Messier, C., and Kembel, S. W. 2017. Leaf bacterial diversity mediates plant diversity and ecosystem function relationships. Nature 546:145-147.

Lamb, T. G., Tonkyn, D. W., and Kluepfel, D. A. 1996. Movement of Pseudomonas aureofaciens from the rhizosphere to aerial plant tissue. Can. J. Microbiol. 42:1112-1120.

Lamichhane, J. R., You, M. P., Laudinot, V., Barbetti, M. J., and Aubertot, J. 2020. Revisiting sustainability of fungicide seed treatments for field crops. Plant Dis. 104:610-623.

Lau, J. A., and Lennon, J. T. 2012. Rapid responses of soil microorganisms improve plant fitness in novel environments. Proc. Natl. Acad. Sci. U.S.A. 109:14058-14062.

Lauber, C. L., Ramirez, K. S., Aanderud, Z., Lennon, J., and Fierer, N. 2013. Temporal variability in soil microbial communities across land-use types. ISME J. 7:1641-1650

Leopold, D. R., and Busby, P. E. 2020. Host genotype and colonist arrival order jointly govern plant microbiome composition and function. Curr. Biol. 30: 3260-3266.e5

Lindow, S. E., and Brandl, M. T. 2003. Microbiology of the phyllosphere. Appl. Environ. Microbiol. 69:1875-1883.

Longley, R., Noel, Z. A., Benucci, G. M. N., Chilvers, M. I., Trail, F., and Bonito, G. 2020. Crop management impacts the soybean (Glycine max) Microbiome. Front. Microbiol. 11:1116.

Maignien, L., DeForce, E. A., Chafee, M. E., Eren, A. M., and Simmons, S. L. 2014. Ecological succession and stochastic variation in the assembly of Arabidopsis thaliana phyllosphere communities. MBio 5:e00682-13.

Mashiane, R. A., Ezeokoli, O. T., Adeleke, R. A., and Bezuidenhout, C. C. 2017. Metagenomic analyses of bacterial endophytes associated with the phyllosphere of a Bt maize cultivar and its isogenic parental line from South Africa. World J. Microbiol. Biotechnol. 33:80.

McMurdie, P. J., and Holmes, S. 2013. phyloseq: An R package for reproducible interactive analysis and graphics of microbiome census data. PLoS One 8:e61217.

McMurdie, P. J., and Holmes, S. 2014. Waste not, want not: Why rarefying microbiome data is inadmissible. PLOS Comput. Biol. 10:e1003531.

Morris, C. E., Barny, M. A., Berge, O., Kinkel, L. L., and Lacroix, C. 2017. Frontiers for research on the ecology of plant-pathogenic bacteria: Fundamentals for sustainability. Mol. Plant Pathol. 18:308-319.

Mueller, D., Wise, K., and Sisson, A. 2018. Corn disease loss estimates from the United States and Ontario, Canada-2017. Corn Disease Management, CPN2007-17-W. Crop Protection Network. https://crop-protectionnetwork.s3.amazonaws.com/publications/cpn-2007-17-corn-disease-lossestimates-2017.pdf

Naylor, D., DeGraaf, S., Purdom, E., and Coleman-Derr, D. 2017. Drought and host selection influence bacterial community dynamics in the grass root microbiome. ISME J. 11:2691-2704.

Nelson, E. B. 2004. Microbial dynamics and interactions in the spermosphere. Annu. Rev. Phytopathol. 42:271-309.

Nettles, R., Watkins, J., Ricks, K., Boyer, M., Licht, M., Atwood, L. W., Peoples, M., Smith, R. G., Mortensen, D. A., and Koide, R. T. 2016. Influence of pesticide seed treatments on rhizosphere fungal and bacterial communities and leaf fungal endophyte communities in maize and soybean. Appl. Soil Ecol. 102:61-69.

Nguyen, N. H., Song, Z., Bates, S. T., Branco, S., Tedersoo, L., Menke, J., Schilling, J. S., and Kennedy, P. G. 2016. FUNGuild: An open annotation tool for parsing fungal community datasets by ecological guild. Fungal Ecol. 20: $241-248$
Noel, Z. A., Chang, H. X., and Chilvers, M. I. 2020. Variation in soybean rhizosphere oomycete communities from Michigan fields with contrasting disease pressures. Appl. Soil Ecol. 150:103435.

Oksanen, J., Blanchet, F. G., Friendly, M., Kindt, R., Legendre, P., McGlinn, D., Minchin, P. R., O’Hara, R. B., Simpson, G. L., Solymos, P., Stevens, M. H. H., Szoecs, E., and Wagner, H. 2016. vegan: Community Ecology Package. https:/cran.r-project.org/web/packages/vegan/index.html

Oneto, D. L., Golan, J., Mazzino, A., Pringle, A., and Seminara, A. 2020. Timing of fungal spore release dictates survival during atmospheric transport. Proc. Natl. Acad. Sci. U.S.A. 117:5134-5143.

Ottesen, A. R., Pena, A. G., White, J. R., Pettengill, J. B., Li, C., Allard, S. Rideout, S., Allard, M., Hill, T., Evans, P., Strain, E., Musser, S., Knight, R., and Brown, E. 2013. Baseline survey of the anatomical microbial ecology of an important food plant: Solanum lycopersicum (tomato). BMC Microbiol. 13:114.

Pastor, F. J., and Guarro, J. 2008. Alternaria infections: Laboratory diagnosis and relevant clinical features. Clin. Microbiol. Infect. 14:734-746.

Paulson, J. N., Stine, O. C., Bravo, H. C., and Pop, M. 2013. Differential abundance analysis for microbial marker-gene surveys. Nat. Methods 10: 1200-1202.

Peay, K. G., Schubert, M. G., Nguyen, N. H., and Bruns, T. D. 2012. Measuring ectomycorrhizal fungal dispersal: Macroecological patterns driven by microscopic propagules. Mol. Ecol. 21:4122-4136.

Peiffer, J. A., Spor, A., Koren, O., and Jin, Z. 2013. Diversity and heritability of the maize rhizosphere microbiome under field conditions. Proc. Natl. Acad. Sci. U.S.A. 110:6548-6553.

Pringle, A., Brenner, M. P., Fritz, J. A., Roper, M., and Seminara, A. 2016. Reaching the wind: Boundary layer escape as a constraint on ascomycete spore dispersal. In: The Fungal Community: Its Organization and Role in the Ecosystem. J. Dighton and J. F. White, eds. CRC Press, Boca Raton, FL, U.S.A.

Pringle, A., Vellinga, E., and Peay, K. 2015. The shape of fungal ecology: Does spore morphology give clues to a species' niche? Fungal Ecol. 17:213-216.

Rascovan, N., Carbonetto, B., Perrig, D., Díaz, M., Canciani, W., Abalo, M., Alloati, J., González-Anta, G., and Vazquez, M. P. 2016. Integrated analysis of root microbiomes of soybean and wheat from agricultural fields. Sci. Rep. 6:28084.

Remus-Emsermann, M. N. P., Lücker, S., Müller, D. B., Potthoff, E., Daims, H., and Vorholt, J. A. 2014. Spatial distribution analyses of natural phyllospherecolonizing bacteria on Arabidopsis thaliana revealed by fluorescence in situ hybridization. Environ. Microbiol. 16:2329-2340.

Remus-Emsermann, M. N. P., and Schlechter, R. O. 2018. Phyllosphere microbiology: At the interface between microbial individuals and the plant host. New Phytol. 218:1327-1333.

Rojas, J. A., Jacobs, J. L., Napieralski, S., Karaj, B., Bradley, C. A., Chase, T., Esker, P. D., Giesler, L. J., Jardine, D. J., Malvick, D. K., Markell, S. G., Nelson, B. D., Robertson, A. E., Rupe, J. C., Smith, D. L., Sweets, L. E., Tenuta, A. U., Wise, K. A., and Wise, M. I. 2017. Oomycete species associated with soybean seedlings in North America-Part II: Diversity and ecology in relation to environmental and edaphic factors. Phytopathology 107:293-304.

Ryffel, F., Helfrich, E. J., Kiefer, P., Peyriga, L., Portais, J.-C., Piel, J., and Vorholt, J. A. 2016. Metabolic footprint of epiphytic bacteria on Arabidopsis thaliana leaves. ISME J. 10:632-643.

Sapkota, R., Jørgensen, L. N., and Nicolaisen, M. 2017. Spatiotemporal variation and networks in the mycobiome of the wheat canopy. Front. Plant Sci. 8:1357.

Sapkota, R., Knorr, K., Jørgensen, L. N., O'Hanlon, K. A., and Nicolaisen, M. 2015. Host genotype is an important determinant of the cereal phyllosphere mycobiome. New Phytol. 207:1134-1144.

Schumann, G. L., and D’Arcy, C. L. 2010. Essential Plant Pathology. American Phytopathological Society, St. Paul, MN, U.S.A.

Shade, A., McManus, P. S., and Handelsman, J. 2013. Unexpected diversity during community succession in the apple flower microbiome. MBio 4: e00602-12.

Stolze-Rybczynski, J. L., Cui, Y., Stevens, H. H., Davis, D. J., Fischer, M. W. F., and Money, N. P. 2009. Adaptation of the spore discharge mechanism in the Basidiomycota. PLoS One 4:e4163.

Strom, N., Weiming, H., Chen, S., and Bushley, K. 2019. Continuous monoculture shapes root and rhizosphere fungal communities of corn and soybean in soybean cyst nematode-infested soil. Phytobiomes J. 3:300-314.

Tackenberg, M., Volkmar, C., and Dammer, K.-H. 2016. Sensor-based variable-rate fungicide application in winter wheat. Pest Manage. Sci. 72: 1888-1896.

Toju, H., Tanabe, A. S., Yamamoto, S., and Sato, H. 2012. High-coverage ITS primers for the DNA-based identification of Ascomycetes and Basidiomycetes in environmental samples. PLoS One 7:e40863.

Trail, F. 2007. Fungal cannons: Explosive spore discharge in the Ascomycota. FEMS Microbiol. Lett. 276:12-18. 
Trail, F., Gaffoor, I., and Vogel, S. 2005. Ejection mechanics and trajectory of the ascospores of Gibberella zeae (anamorph Fusarium graminearum). Fungal Genet. Biol. 42:528-533.

USDA-NASS. 2016. Crop Production 2015 Summary. United States Department of Agriculture National Agricultural Statistics Service. https:// iowaculture.gov/sites/default/files/primary-sources/pdfs/history-educationpss-agriculture-summary-PDF-NEW.pdf

van der Heijden, M. G. A., Klironomos, J. N., Ursic, M., Moutoglis, P., Streitwolf-Engel, R., Boller, T., Wiemken, A., and Sanders, I. R. 1998. Mycorrhizal fungal diversity determines plant biodiversity, ecosystem variability and productivity. Nature 396:69-72.

Vellend, M. 2010. Conceptual synthesis in community ecology. Q. Rev. Biol. 85:183-206.

Vogel, C., Bodenhausen, N., Gruissem, W., and Vorholt, J. A. 2016. The Arabidopsis leaf transcriptome reveals distinct but also overlapping responses to colonization by phyllosphere commensals and pathogen infection with impact on plant health. New Phytol. 212:192-207.

Vorholt, J. A. 2012. Microbial life in the phyllosphere. Nature 10:828-840.

Wang, Q., Garrity, G. M., Tiedje, J. M., and Cole, J. R. 2007. Naive Bayesian classifier for rapid assignment of rRNA sequences into the new bacterial taxonomy. Appl. Environ. Microbiol. 73:5261-5267.

Warnes, G. R., Bolker, B., Bonebakker, L., Gentleman, R., Huber, W., Liaw, A., Lumley, T., Maechler, M., Magnusson, A., Moeller, S., Schwartz, M.,
Venables, B., and Galili, T. 2016. gplots: Various R programming tools for plotting data. https://rdrr.io/cran/gplots/

Warner, N. J., Allen, M. F., and MacMahon, J. A. 1987. Dispersal agents of vesicular-arbuscular mycorrhical fungi in a disturbed arid ecosystem. Mycologia 79:721-730.

Watkinson, S. C. 2016. Mutualistic symbiosis between fungi and autotrophs. Pages 205-243 in: The Fungi, 3rd Ed. S. C. Watkinson, L. Boddy, and N. P. Mooney, eds. Academic Press, Oxford, U.K.

Wattenburger, C. J., Halverson, L. J., and Hofmockel, K. S. 2019. Agricultural management affects root-associated microbiome recruitment over maize development. Phytobiomes J. 3:260-272.

Webster, J., Davey, R. A., and Ingold, C. T. 1984. Origin of the liquid in Buller's drop. Trans. Br. Mycol. Soc. 83:524-527.

Webster, J., and Weber, R. W. S. 2007. Introduction to Fungi, 3rd Ed. Cambridge University Press, Cambridge, U.K.

Wickham, H. 2009. ggplot2: Elegant Graphics for Data Analysis. Springer, New York, NY, U.S.A.

Wu, K., Yuan, S., Xun, G., Shi, W., Pan, B., Guan, H., Shen, B., and Shen, Q. 2015. Root exudates from two tobacco cultivars affect colonization of Ralstonia solanacearum and the disease index. Eur. J. Plant Pathol. 141:667-667.

Zhang, Y., Kastman, E. K., Guasto, J. S., and Wolfe, B. E. 2018. Fungal networks shape the dynamics of bacterial dispersal and community assembly in cheese rind microbiomes. Nat. Commun. 9:336. 